\title{
Analysis of Multi-Stakeholders' Behavioral Strategies Considering Public Participation under Carbon Taxes and Subsidies: An Evolutionary Game Approach
}

\author{
Wanting Chen ${ }^{1,2}$ (D) and Zhi-Hua Hu ${ }^{1, *(D)}$ \\ 1 Logistics Research Center, Shanghai Maritime University, Shanghai 201306, China; wontingshen@sina.cn \\ 2 School of Business, Hainan Tropical Ocean University, Sanya 572022, China \\ * Correspondence: zhhu@shmtu.edu.cn
}

Received: 2 January 2020; Accepted: 26 January 2020; Published: 31 January 2020

check for updates

\begin{abstract}
Considering public participation in environmental management, we developed a tripartite game model among governments, manufacturers and publics under carbon taxes and subsidies to investigate whether the mutual relationship between governments and the public can urge manufacturers to adopt low-carbon technology by examining the interaction effect among the multi-stakeholders. In this study, we focus on manufactured products without significant low-carbon peculiarity. For these products, consumers have no way to identify which are from low-carbon production and which are not. The results show that governments and the public have a complementary and coordinating relationship indeed. The regulation cost of governments, the supervision reward for the public and the supervision cost of the public can all influence the behavioral strategies among the multi-stakeholders, including governments, manufacturers and the public. With the regulation cost strengthens dramatically, governments can consider increasing the supervision reward to support the public to participate in the management of manufacturers' behaviors. Publics should also actively improve their management ability, and the low cost of public participation in supervision is an effective reflection to make up for the lack of government regulation. The implementation of carbon taxes is more advantageous in urging low-carbon manufacturing than government subsidies for low-carbon production. A complete carbon label system can reflect the low-carbon preferences of consumers to help manufacturers integrate low-carbon behavior into their operational decisions.
\end{abstract}

Keywords: evolutionary game; government; manufacturers; carbon taxes; low-carbon subsidies; public participation

\section{Introduction}

People have witnessed the fast growth of the world economy and the progress of science and technology, which is at the cost of severe environmental pollution and ecological damage. The report released in 2018 by the Global Carbon Project (GCP) notes that global carbon emissions rose sharply in 2017 after a brief plateau from 2014-2016. In 2018, carbon dioxide emissions from fossil fuels reached 37.1 billion tons, up $2 \%$ and surpassing $1.4 \%$ increase in 2017, and confirm a new record [1]. Most countries are trying to realize resource recycling and sustainable development through energy-saving and emission reduction. European Emissions Trading System (EU-ETS) was set up to mandatorily supervise the green emissions of enterprises, while allowing them to trade carbon quotas in 2005 [2]. Countries, such as Sweden, Norway, Finland and Denmark were imposed carbon taxes to control enterprise' carbon emissions [3,4].

The carbon tax, low-carbon subsidy and cap-and-trade have become the key measures to control greenhouse gas emissions, promote technological innovation and optimize industrial structure [5]. 
However, with the frequency and expansion of environmental protection problems, the task of environmental regulation is onerous. On the one hand, the economic characteristics of market stakeholders, the non-exclusivity of natural resources, as well as the asymmetry and imperfection of information will all lead to market failure. On the other hand, the limited rationality of government behavior and the diversity of government goals, there is also the possibility of government failure, due to the unsound government system [6]. Compared with various types of polluting industries, the original management system and policies of government have lagged behind the internal requirements of low-carbon development. It will not effectively form a well binding force on some enterprises and organizations that are high emissions and pollution, nor will it effectively stimulate multi-agent to innovate technologies, promote energy conservation and emission reduction [7].

Environmental protection is a public interest issue. As an important force in environmental protection, public participation has attracted more attention from various nations. Public participation in environmental protection refers to the participation of individuals or third-party organizations outside the government in environmental decision-making and management through a series of formal and informal channels. They evaluate and supervise the environmental behaviors of governments and enterprises, or carry out environmental protection activities directly [8]. The participation of individuals or third-party organizations in environmental management is not only to meet the needs of the transformation of economic development mode, but also to make up for the lack of market and solve the dilemma of government regulation. In 2015, Environmental Protection Act (EPA) in China clearly stipulated rules for public participation, that is, any organization or individual has an obligation to protect the environment and the right to report and file charges against organizations that pollute or damage the environment [9]. Besides, Non-profit organizations (NPOs) as the third-party organizations for environmental protection have gradually developed into the most important environmental protection force after the governments and enterprises [10].

At present, enterprises' low-carbon behaviors are lack of binding force that is mainly guided by the governments and supplemented by the voluntary participation of enterprises. Owing to the manufactured products have no significant low-carbon peculiarity, without carbon labelling, consumers could not be able to distinguish which commodities are made by low-carbon manufacturing and which are not. In view of the limitations of government regulation behaviors and the uncertainty of manufacturers' low-carbon strategies, how to support the third-party supervision of the public through government financial incentives? How to promote cooperation and co-governance between the governments and the public to improve the regulation ability of environmental protection? To promote environmental protection, should the government impose carbon taxes on high-emission manufacturers, or subsidize low-carbon manufacturers? Thinking about these questions in mind, we are attempting to apply evolutionary game theory to solve this problem. This paper develops a tripartite game model among governments, manufacturers and the public under carbon taxes and subsidies. We use this model to explain the influence of the complementary relationship between the government and the public on the behavioral decisions of manufacturers.

The remainder of the study proceeds is structured as follows. The literature review is summarized in Section 2. In Section 3, model hypotheses are listed. We develop a tripartite evolutionary game model among the multi-stakeholders that included governments, manufacturers and the public. The beer industry is chosen as a case study in Section 4, and it theoretically is equal to the other finished commodities that have no significant low-carbon peculiarity. In Section 5, according to the complexity of model and stability analysis, the interaction mechanism among the governments, manufacturers and the public is further experimented by simulation studies to achieve an intuitive understanding. Section 6 shows some conclusions and policy implications. 


\section{Literature Review}

\subsection{The Low-Carbon Policy on Enterprises' Decision-Making}

Low-carbon policies can be divided into two categories: One kind focuses on the use of market-based instruments to deal with the problem of externalities, including carbon trading and emissions trading systems [11,12]. The other kind is an attempt to internalize the externalities of environmental pollution through government intervention, including carbon taxes and subsidies [13].

A cap-and-trade system has been comprehensively explored in academia as one of the most effective mechanisms to achieve emission reduction targets. Jiang et al. [14] systematically reviewed the recent literature on cap-and-trade in China. Given the emission permit price and emission limit, Sabzevar et al. [15] explored the inter-enterprise distribution cap and emission permit price. $\mathrm{Xu}$ et al. [5] investigated the influence of carbon trade price on the optimal production behavior of manufacturers. Wang et al. [16] examined the impact of carbon trading mechanism on production planning and emission reduction strategies of enterprises. Carbon taxes and governmental subsidies, as two major economic incentive policies too $[17,18]$. Considering the government financial intervention, Hafezalkotob [19] explored the competition and cooperation models about price decision and energy saving. Under the carbon taxes, Wang et al. [20] investigated how non-peer firms could cooperate to reduce emissions. He et al. [21] explored the channel structure and pricing decisions for the manufacturers with subsidy policy. According to governmental subsidies, Chen et al. [22] examined how enterprises decide the level of technological innovation and the distribution of innovation costs among partners.

In addition to governments and enterprises, the impact of public consumption preferences is also included in some studies [23,24]. Yenipazarli [25] demonstrated the willingness of consumer demands, competitor behavioral principles and regulatory requirements to motivate enterprises for protecting the environment. About carbon labelling, the results of Feucht and Zander [26] showed that the launch of carbon label did increase the purchase probability of consumers, who were willing to pay a price premium of about $20 \%$ to buy green commodities.

\subsection{The Role of Public Participation in Environmental Protection}

Some scholars focused on public participation in environmental impact assessment (EIA). O'Faircheallaigh [27] applied some models of public participation in policy development to think about how to interpret and evaluate methods for participation in EIA. Glucker et al. [28] comprehensively reviewed the research on public participation in EIA. Wu et al. [29] utilized panel data from 31 provinces in China from 2004 to 2015 to compare the influence of public participation on environmental performance. Simpson and Basta [30] presented four South African EIA case studies and explored the selection of capabilities and functioning of stakeholders in public participation. Some scholars have explored the correlating relationship between public environmental participation and government governance effectiveness based on the difference-in-difference (DID) method [31,32]. NPOs' participation in environmental management is another important form of public participation [33]. Jing et al. [34] explored the obstacles for NPOs to participate and investigated the orientation and development of public participation. Ayana et al. [35] used the policy arrangement approach (PAA) to examine how and to what extent NPOs' strategies influence policy decisions. Compared the public participation in Malaysia and China, Yew and Zhu [10] investigated the role of NPOs in national environmental governance.

Seldom theoretical studies on public participation in environmental protection concentrated on the depth analysis of the interaction mechanism among government, enterprises and the public. The environmental protection behavior of individual public participation is the result of interaction between environmental awareness and social factors, while it of the publics is the game result of various interest groups. How governments, enterprises and public play games in the social system to solve the environmental problems jointly is a problem, we should further study. 


\subsection{The Application of the Evolutionary Game}

The evolutionary game theory (EGT) has the advantage of analyzing mechanisms of interaction among multi-stakeholders, which can be applied in many fields, including business and economics [36,37].

Many scholars have used EGT to examine supply chain management and develop long-term cooperation relationship. Sikhar et al. [38] established a coordination model between producer and retailer to adjudicate their strategies. Ji et al. [39] explored the cooperation trend of multi-stakeholders, and they discussed trading behavior as a strategy and payoff function. Yang et al. [40] explored how the behavior of some members of the supply chain can trigger cascading effects. Government policy is the key factor in promoting the development of a green supply chain. Tian et al. [41] provided system dynamics models about EGT to examine the differences in subsidies to manufacturers and consumers, respectively, and analyzed the relationships among stakeholders, such as government, enterprises and consumers. Under three different scenarios on government policies, Mahmoudi and Rasti-Barzoki [42] used EGT to compare the objectives of government targets and producers, and they also investigated the impact of government taxes and subsidies on producers.

There are much research on the interaction mechanism of the two participants by using the EGT, but little research on the interaction mechanism of the multiple stakeholders considering the participation of third-party organizations. Encarnação et al. [43] applied EGT to investigate the coevolutionary decisions of these multi-participants influenced by different policies and social incentives. Li et al. [44] established the EGT model on the complex network and explored the dynamic influences about government policies on the popularization of electric vehicles under various scale networks. The EGT can timely reflect the complicated relationship among the multi-stakeholders, including suppliers, manufacturers and other agents.

As a summary, there is no literature to explore enterprises' decision-making considering public participation under carbon taxes and subsidies by using evolutionary game theory. In contrast, from the above literature, our research examines these problems from both government and public perspectives. Thus, our main contribution of this study can be summarized in the three aspects. Instead of the game between the governments and the enterprises, this paper first considered public participation in environmental protection, and develop a tripartite game model among governments, manufacturers and the public according to the complex relationships of multi-stakeholders. Second, owing to the manufactured goods have no significant low-carbon peculiarity, we set the price of the products to be the same, and taking into account the carbon taxes and subsidies, consumer purchase preferences simultaneously. Last, we focused on an in-depth analysis of the interaction mechanism among the government, manufacturers and publics-and we investigate whether the complementary relationship between government and public can help manufacturers to implement low-carbon strategies.

\section{Model and Stability Analysis}

\subsection{Model Assumption}

The multi-players are, respectively, governments $(\mathrm{G})$, manufacturers $(\mathrm{M})$ and publics $(\mathrm{P})$, both of which are economical and limited rationality. To simplify the problem, our research mainly analyzes the product $\mathrm{K}$ manufactured by enterprises. Suppose product $\mathrm{K}$ has no significant no difference in terms of functions, whether using low-carbon technology or not. The product $\mathrm{K}$ made through low-carbon technologies we regard as the low-carbon product $\mathrm{K}$-otherwise, we treat as the ordinary product $\mathrm{K}$.

Governments could regulate manufacturers under carbon taxes and subsidies or not. Suppose the probability of government regulation is $x(0 \leq x \leq 1)$, then the probability of not regulating is $(1-x)$; Manufacturers could apply low-carbon manufacturing or not too. Suppose the probability of manufacturer adopting low-carbon technology is $y(0 \leq y \leq 1)$, then the probability of not adopting is $(1-y)$; the public could supervise the behavior form manufacturers or not too. Suppose the probability 
of publics performing supervision is $z(0 \leq z \leq 1)$, then the probability of public not performing is $(1-z)$.

Relevant notations are defined in the model, and their meanings are explained as follows:

(i) Considering the product $\mathrm{K}$ have no low-carbon peculiarity, we assume that the unit sale price of product $\mathrm{K}$ is $p_{k}$ whether it manufactured with low-carbon technology or not. If the manufacturer produces $\mathrm{K}$ adopting low-carbon technology, the unit $\operatorname{cost}$ is $c_{k}^{l}$, or the unit cost of the ordinary product $\mathrm{K}$ is $c_{k}^{g}$.

(ii) Suppose consumer preferences of purchasing product $K$ is $\delta(0 \leq \delta \leq 1), \delta \in(0.5,1]$ represents the preference interval of purchasing low-carbon product $K$, and $\delta \in[0,0.5)$ represents the preference interval of purchasing ordinary product $\mathrm{K}$. On the premise of no carbon labelling, consumers' purchase preference is determined to be neutral, i.e., $\delta=0.5$. Suppose market demand for product $\mathrm{K}$ is $\varphi$, and monthly profits for the manufacturer of low-carbon product $\mathrm{K}$ is $\pi_{k}^{l}=\left(p_{k}-c_{k}^{l}\right) \times \delta \varphi$, monthly profits for the manufacturer of ordinary product $\mathrm{K}$ is $\pi_{k}^{g}=\left(p_{k}-c_{k}^{g}\right) \times(1-\delta) \times \varphi$.

(iii) Suppose governments regulate manufacturers under carbon taxes, and subsidies need to be paid for the corresponding $\operatorname{cost} C_{r}$. If manufacturers produce low-carbon product, the government will give them subsidies $S$ and get the environmental benefits $H_{g 1}$; If manufacturers produce the ordinary product, the government will levy carbon taxes $T$ on them and get the environmental losses $H_{g 2}$, then need to be paid for the environmental governance fees $C_{g}$ to deal with pollutions.

(iv) With participation in environmental management, the public need to pay for the corresponding $\operatorname{cost} C_{S}$ to supervise manufacturers. If manufacturers adopt low-carbon manufacturing, publics will enjoy the good environmental quality $H_{p}$; If the manufacturer produces ordinary product $\mathrm{K}$ without government regulation, publics find out and report to the government, then the government will impose carbon taxes on the manufacturer and give a supervision reward $R$ to the public. Besides, the environmental pollution damages caused by manufacturers without low-carbon technology is $\mathrm{D}$. The interactive relationship among governments, manufacturers and the public is shown in Figure 1.

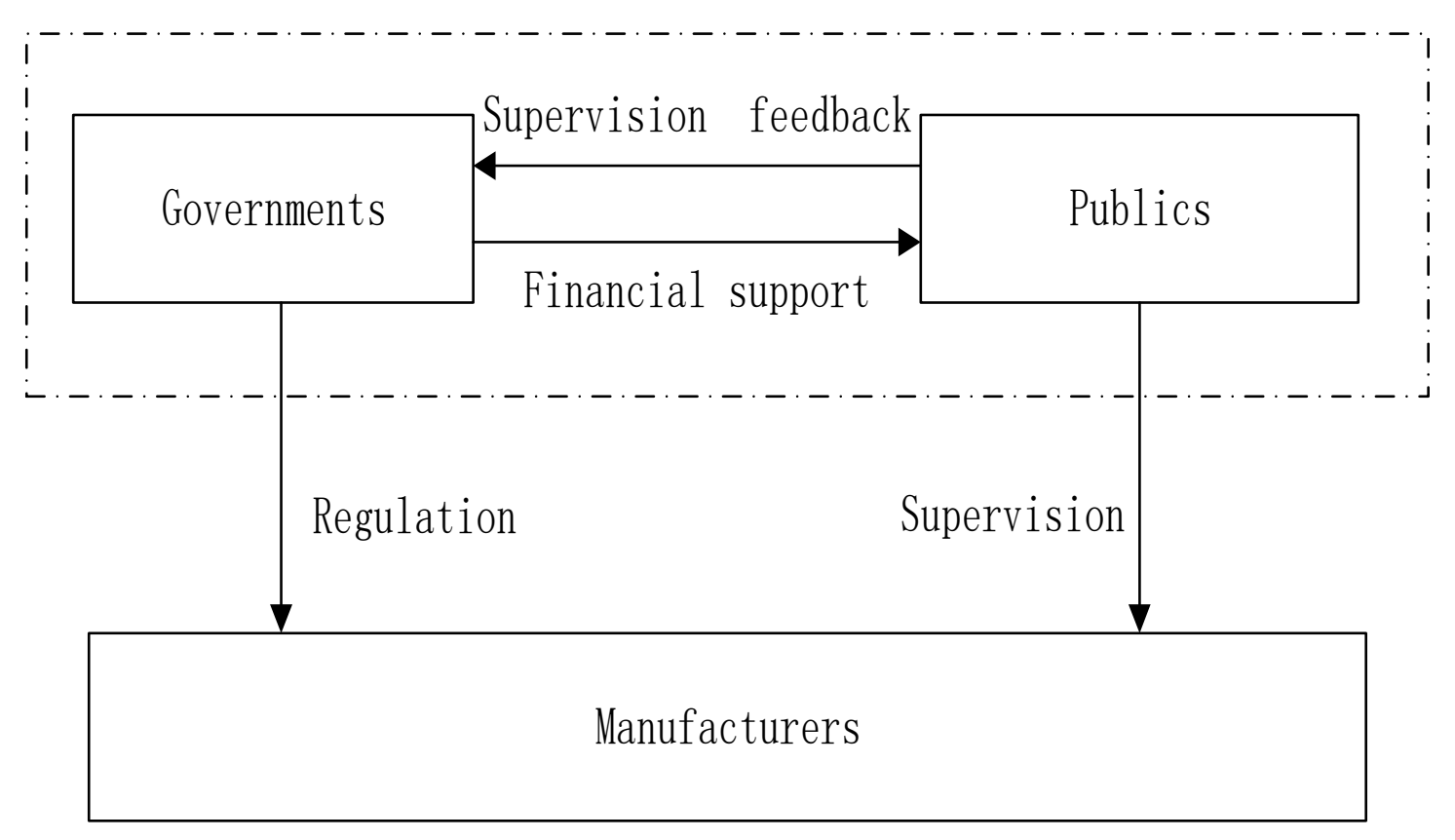

Figure 1. The tripartite game diagram among governments, manufacturers and the public. 
These relevant notations and explanations are described in Table 1.

Table 1. Notations and explanations.

\begin{tabular}{cc}
\hline Parameters & Explanations \\
\hline$p_{k}$ & Unit sale price of $\mathrm{K}$ \\
$c_{k}^{l}$ & Unit cost of low-carbon product $\mathrm{K}$ of manufactures \\
$c_{k}^{8}$ & Unit cost of ordinary K of manufactures \\
$\pi_{k}^{l}$ & Monthly profit for low-carbon product $\mathrm{K}$ of manufactures \\
$\pi_{k}^{8}$ & Monthly profit for ordinary $\mathrm{K}$ of manufactures \\
$\varphi$ & Monthly market demand of $\mathrm{K}$ \\
$\delta$ & Consumer preference for purchasing $\mathrm{K}$ \\
$C_{r}$ & Regulation costs of governments \\
$C_{g}$ & Environmental governance fees of governments \\
$C_{s}$ & Supervision cost of publics \\
$H_{g}$ & Environmental benefits for governments \\
$H_{g 2}$ & Environmental losses for governments \\
$H_{p}$ & Environmental quality for publics \\
$S$ & Subsidies for low-carbon $\mathrm{K}$ \\
$T$ & Carbon taxes for ordinary $\mathrm{K}$ \\
$R$ & Rewards of publics for supervision and report \\
$D$ & Damages caused by environmental pollution of publics \\
\hline Variables & Explanations \\
\hline$x$ & Probability of governments regulation $(0 \leq x \leq 1)$ \\
$y$ & Probability of manufactures adoption $(0 \leq y \leq 1)$ \\
$z$ &
\end{tabular}

\subsection{Model Formulation}

Based on the above hypothesis, the evolutionary game payoff matrix among governments, manufacturers and the public is established in Table 2.

Table 2. Payoff matrix of governments, manufacturers and publics.

\begin{tabular}{|c|c|c|c|c|c|}
\hline & & \multicolumn{4}{|c|}{ Publics (P) } \\
\hline & & \multicolumn{2}{|c|}{ Supervise $(z)$} & \multicolumn{2}{|c|}{ Not Supervise $(1-z)$} \\
\hline & & \multicolumn{2}{|c|}{ Manufacturers (M) } & \multicolumn{2}{|c|}{ Manufacturers (M) } \\
\hline & & Adopt $(y)$ & Not Adopt $(1-y)$ & Adopt (y) & Not Adopt $(1-y)$ \\
\hline \multirow{2}{*}{$\begin{array}{c}\text { Governments } \\
\text { (G) }\end{array}$} & Regulate $(x)$ & $\begin{array}{c}H_{g 1}-S-C_{r} \\
\pi_{k}^{l}+S \\
\mathrm{H}_{p}-C_{s}\end{array}$ & $\begin{array}{c}H_{g 2}+\mathrm{T}-C_{r}-C_{g} \\
\pi_{k}^{g}-T \\
-C_{s}-D\end{array}$ & $\begin{array}{c}H_{g 1}-S-C_{r} \\
\pi_{k}^{l}+S \\
\mathrm{H}_{p}\end{array}$ & $\begin{array}{c}H_{g 2}+\mathrm{T}-C_{r}-C_{g} \\
\pi_{k}^{g}-T \\
-D\end{array}$ \\
\hline & $\begin{array}{l}\text { Not regulate } \\
\qquad(1-x)\end{array}$ & $\begin{array}{c}H_{g} \\
\pi_{k}^{l} \\
\mathrm{H}_{p}-\mathrm{C}_{s}\end{array}$ & $\begin{array}{c}-C_{g}+T-R \\
\pi_{k}^{g}-T \\
-C_{s}-D+R\end{array}$ & $\begin{array}{l}H_{g} \\
\pi_{k}^{l} \\
\mathrm{H}_{p}\end{array}$ & $\begin{array}{c}-C_{g} \\
\pi_{k}^{g} \\
-D\end{array}$ \\
\hline
\end{tabular}

For the governments, the expected utility of "Regulation" and "No regulation" is $\mathrm{E}_{g 1}, \mathrm{E}_{g 2}$, and the average utility of them is $E_{g}$, which are described by Equations (1)-(3), respectively.

$$
\begin{gathered}
\mathrm{E}_{g 1}=T-(S+T) y-C_{r}+(1-y)\left(-C_{g}+H_{g 2}\right)+y H_{g 1} \\
\mathrm{E}_{g 2}=(-1+y)\left((R-T) z+C_{\mathrm{g}}-H_{g 2}\right)+y H_{g 1} \\
\mathrm{E}_{g}=x(T-(S+T) y)-(R-T)(1-x)(1-y) z-x C_{r}+(1-y)\left(-C_{\mathrm{g}}+H_{g 2}\right)+y H_{g 1}
\end{gathered}
$$


For the manufacturers, the expected utility of "Adoption" and "No adoption" is $\mathrm{E}_{m 1}, \mathrm{E}_{m 2}$, and the average utility of them is $\mathrm{E}_{m}$, which are described by Equations (4)-(6), respectively.

$$
\begin{gathered}
\mathrm{E}_{m 1}=S x+\pi_{k}^{l} \\
\mathrm{E}_{m 2}=-T x(1-z)-T z+\pi_{k}^{g} \\
\mathrm{E}_{m 1}=y\left(S x+\pi_{k}^{l}\right)+(1-y)\left(-T x-T(1-x) z+\pi_{k}^{g}\right)
\end{gathered}
$$

For the public, the expected utility of "Supervision" and "No supervision" is $\mathrm{E}_{p 1}, \mathrm{E}_{p 2}$, and the average utility of them is $E_{p}$, which are described by Equations (7)-(9), respectively.

$$
\begin{gathered}
\mathrm{E}_{s 1}=R-R x-R y+R x y-C_{s}-(1-y) D+y H_{p} \\
\mathrm{E}_{s 2}=-(1-y) D+y H_{p} \\
\mathrm{E}_{s}=-z C_{s}+(1-y)(R(1-x) z+D)+y H_{p}
\end{gathered}
$$

Referring to the work of Friedman [45], the process of strategy selection among game players used to model the replicator dynamic equation. The core of the equation is that the number of individuals using more successful strategies in a group will gradually increase, thus, changing the possibility of game players using various strategies in this group.

Thus, the replicator dynamic equation of governments' behavioral strategy in Equation (1), which was obtained by Equations (1)-(3) in the Appendix A.

$$
F(x)=\frac{d x}{d t}=x(1-x)\left(T(1-y)(1-z)+R z-y(S+R z)-C_{r}\right)
$$

Similarly, the replicator dynamic equation of manufacturers' behavioral strategy in Equation (2), which was obtained by (4)-(6) in the Appendix A.

$$
F(y)=\frac{d y}{d t}=y(1-y)\left(S x+T(x+z-x z)+\pi_{k}^{l}-\pi_{k}^{g}\right)
$$

Similarly, the replicator dynamic equation of the public's behavioral strategy in Equation (3), which was obtained by (7)-(10) in the Appendix A.

$$
F(z)=\frac{d z}{d t}=z(1-z)\left(R(1-x)(1-y)-C_{s}\right)
$$

The replicator dynamic system among governments, manufacturers and the public is composed of Equations (10)-(12).

\subsection{Model Solution}

\subsubsection{The Replicator Dynamic Behavior of Governments}

According to the stability of system dynamics theory and the characteristics of evolutionary game theory, the necessary conditions that the first derivative of Equation (10) is less than zero must be satisfied to reach the governments' evolutionary stability state, i.e., $F^{\prime}(x)<0$.

$$
F^{\prime}(x)=\frac{d F(x)}{d x}=(1-2 x)\left(T(1-y)(1-z)+R z-y(S+R z)-C_{r}\right)
$$

The behavioral strategies of governments are analyzed as follows: 
(1) If $y=\frac{T+z(R-T)-C_{r}}{S+T+z(R-T)}$ or $=\frac{T(1-y)+S y+C_{r}}{(T-R)(1-y)}$, then $F^{\prime}(x)=\frac{d F(x)}{d x}=0$. It means all $x$ values belong to an evolutionary stable state, and the corresponding replicator dynamic phase diagram is shown in Figure 2a.

(2) If $y>\frac{T+z(R-T)-C_{r}}{S+T+z(R-T)}$ or $>\frac{T(1-y)+S y+C_{r}}{(T-R)(1-y)}$, then $F^{\prime}(x)=\frac{d F(x)}{d x} \mid x=1<0$ and $F^{\prime}(x)=\frac{d F(x)}{d x} \mid x=0>0$. $\mathrm{X}=1$ is an evolutionary stable point and $\mathrm{x}=0$ is a non-evolutionary stable point, the corresponding replicator dynamic phase diagram is shown in Figure $2 b$.

(3) If $y<\frac{T+z(R-T)-C_{r}}{S+T+z(R-T)}$ or $z<\frac{T(1-y)+S y+C_{r}}{(T-R)(1-y)}$, then $F^{\prime}(x)=\frac{d F(x)}{d x} \mid x=0<0$ and $F^{\prime}(x)=\frac{d F(x)}{d x} \mid x=1>0$. $\mathrm{X}=0$ is an evolutionary stable point and $\mathrm{x}=1$ is a non-evolutionary stable point, the corresponding replicator dynamic phase diagrams are shown in Figure 2c.

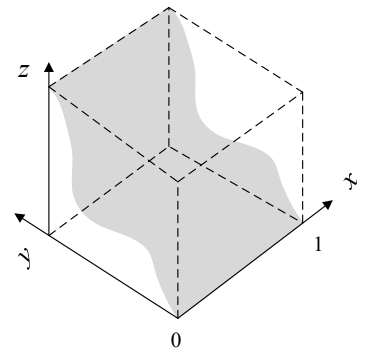

(a)

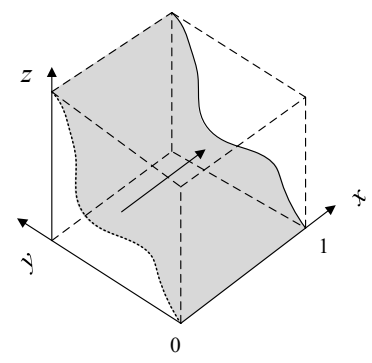

(b)

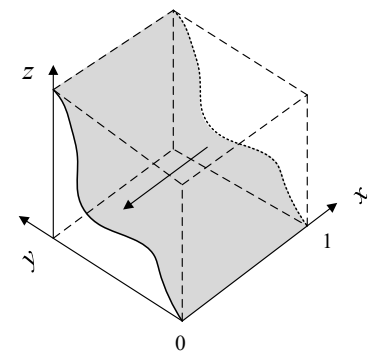

(c)

Figure 2. The replicator dynamic phase diagrams of governments.

\subsubsection{The Replicator Dynamic Behavior of Manufacturers}

Similarly, the necessary conditions of Equation (11), i.e., $F^{\prime}(y)<0$.

$$
F^{\prime}(y)=\frac{d F(y)}{d y}=(1-2 y)\left(S x+T(x+z-x z)+\pi_{k}^{l}-\pi_{k}^{g}\right)
$$

The behavioral strategies of manufacturers are analyzed as follows:

(1) If $x=-\frac{T z+\pi_{k}^{l}-\pi_{k}^{g}}{S+T(1-z)}$ or $z=\frac{(S+T) x+\pi_{k}^{l}-\pi_{k}^{g}}{-T(1-x)}$, then $F^{\prime}(y)=\frac{d F(y)}{d y}=0$. It means that all $y$ values belong to an evolutionary stable state, and the corresponding replicator dynamic phase diagram is shown in Figure 3a.

(2) If $x>-\frac{T z+\pi_{k}^{l}-\pi_{k}^{g}}{S+T(1-z)}$ or $z>\frac{(S+T) x+\pi_{k}^{l}-\pi_{k}^{g}}{-T(1-x)}$, then $F^{\prime}(y)=\frac{d F(y)}{d y} \mid y=1<0$ and $F^{\prime}(y)=\frac{d F(y)}{d y} \mid y=0>0$. $\mathrm{y}=1$ is an evolutionary stable point and $\mathrm{y}=0$ is a non-evolutionary stable point, the corresponding replicator dynamic phase diagram is shown in Figure $3 b$.

(3) If $x<-\frac{T z+\pi_{k}^{l}-\pi_{k}^{g}}{S+T(1-z)}$ or $z<\frac{(S+T) x+\pi_{k}^{l}-\pi_{k}^{g}}{-T(1-x)}$, then $F^{\prime}(y)=\frac{d F(y)}{d y} \mid y=0<0$ and $F^{\prime}(y)=\frac{d F(y)}{d y} \mid y=1>0$. $\mathrm{y}=0$ is an evolutionary stable point and $\mathrm{y}=1$ is a non-evolutionary stable point, the corresponding replicator dynamic phase diagrams are shown in Figure 3c.

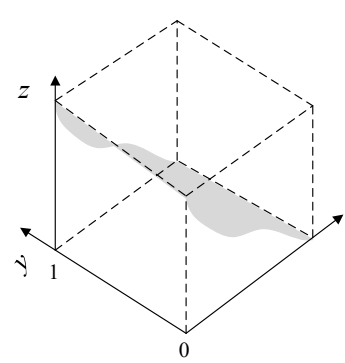

(a)

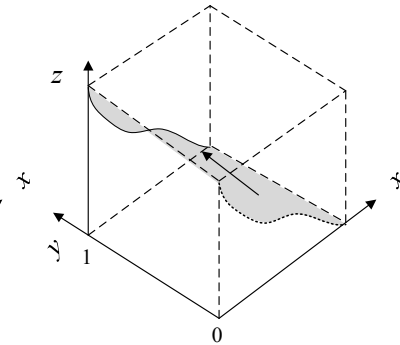

(b)

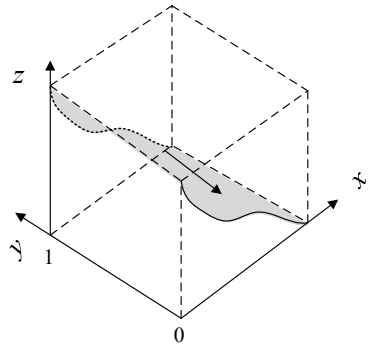

(c)

Figure 3. The replicator dynamic phase diagrams of manufacturers. 


\subsubsection{The Replicator Dynamic Behavior of Publics}

Similarly, the necessary conditions of Equation (12), i.e., $F^{\prime}(z)<0$.

$$
F^{\prime}(z)=\frac{d F(z)}{d z}=(1-2 z)\left(R(1-x)(1-y)-C_{s}\right)
$$

The behavioral strategy of publics is analyzed as follows:

(1) If $x=1-\frac{C_{s}}{R(1-y)}$ or $y=1-\frac{C_{s}}{R(1-x)}$, then $F^{\prime}(z)=\frac{d F(z)}{d z}=0$. It means that all $z$ values belong to an evolutionary stable state, and the corresponding replicator dynamic phase diagram is shown in Figure 4a.

(2) If $x>1-\frac{C_{s}}{R(1-y)}$ or $y>1-\frac{C_{s}}{R(1-x)}$, then $F^{\prime}(z)=\frac{d F(z)}{d z} \mid z=1<0$ and $F^{\prime}(z)=\frac{d F(z)}{d z} \mid z=0>0$. $z=1$ is an evolutionary stable point and $z=0$ is a non-evolutionary stable point, the corresponding replicator dynamic phase diagram is shown in Figure $4 \mathrm{~b}$.

(3) If $x<1-\frac{C_{s}}{R(1-y)}$ or $y<1-\frac{C_{s}}{R(1-x)}$, then $F^{\prime}(z)=\frac{d F(z)}{d z} \mid z=0<0$ and $F^{\prime}(z)=\frac{d F(z)}{d z} \mid z=1>0$. $z=0$ is an evolutionary stable point and $z=1$ is a non-evolutionary stable point, the corresponding replicator dynamic phase diagram is shown in Figure 4c.

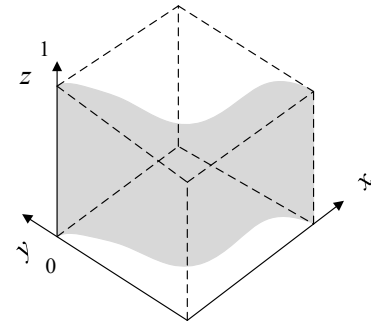

(a)

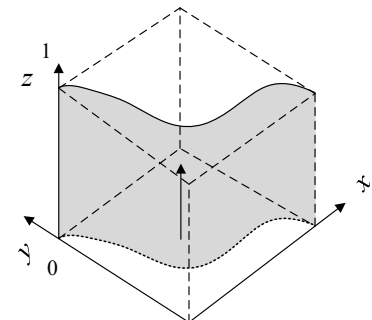

(b)

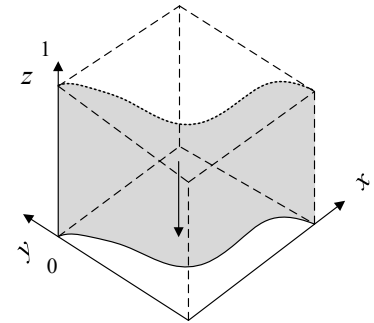

(c)

Figure 4. The replicator dynamic phase diagrams of publics.

From the above analysis, we can know that the strategic behavior of either player is related to it of the other two stakeholders. Thus, we cannot intuitively understand and analyze the strategic interaction among governments, manufacturers and the public. Then, we will further explore the evolutionary stable strategy (ESS) among them from the perspective of the three stakeholders involved in the next section.

\subsection{Stability Analysis}

The replicator dynamic equation reflects the strategy selection process of all stakeholders that are finite rationality through learning and limitation. To seek the ESS, let $F(x)=0, F(y)=0, F(z)=0$, and the equilibrium points $(0,0,0),(1,0,0),(0,1,0),(0,0,1),(1,1,0),(1,0,1),(0,1,1),(1,1,1)$ can be solved. The boundary of the evolutionary game solution domain $\Omega$ is formed from the eight equilibrium points. The region among them can be named the equilibrium solution domain $\Omega$ of the tripartite evolutionary game, i.e., $\Omega=\{(\mathrm{x}, \mathrm{y}, \mathrm{z}) \mid 0<\mathrm{x}<1,0<\mathrm{y}<1,0<\mathrm{z}<1\}$.

In the solution domain $\Omega$ of trilateral game, there is also an equilibrium point $(x, y, z)$ where satisfy Equation system (16).

$$
\left\{\begin{array}{c}
T(1-y)(1-z)+R z-y(S+R z)-C_{r}=0 \\
S x+T(x+z-x z)+\pi_{k}^{l}-\pi_{k}^{g}=0 \\
R(1-x)(1-y)-C_{s}=0
\end{array}\right.
$$

The method to determine the equilibrium point is proposed by Friedman [45] to analyze the Jacobian matrix and eigenvalues of the replicator dynamic system at the equilibrium point. According 
to Lyapunov [46] stability theory, if all eigenvalues of equilibrium point are negative real parts, the replicator dynamic system is stable, then the corresponding equilibrium point is an ESS. Otherwise, it is unstable, and then the corresponding equilibrium point is a saddle point.

Thus, the Jacobian matrix is as follows:

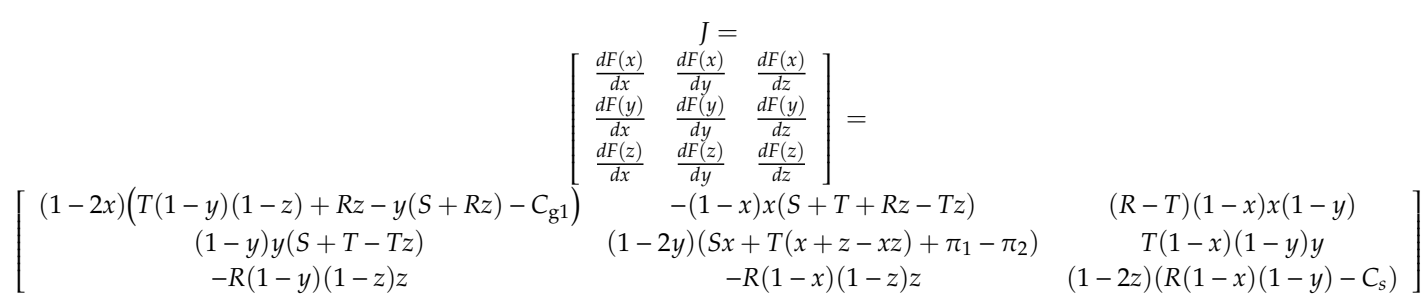

Proposition 1. If $T<C_{r}, \pi_{k}^{l}<\pi_{k}^{g}, R<C_{s}$ are true synchronously, the equilibrium point $(0,0,0)$ is an ESS. Otherwise, the equilibrium point $(0,0,0)$ is a saddle point (Proof A1 see in the Appendix A).

Proposition 1 shows the behavioral strategies among governments, manufacturers and the public are in a balanced and stable state. However, such a balance is a worse state that is not the problem our research wants to discuss.

Proposition 2. If $T>C_{r}, \pi_{k}^{l}+S<\pi_{k}^{g}-T$ are true synchronously, the equilibrium point $(1,0,0)$ is an ESS. Otherwise, the equilibrium point $(1,0,0)$ is a saddle point (Proof A2 see in the Appendix A).

Proposition 2 shows that although the government implements regulation, it cannot exert binding force on the behavior of manufacturers in this scenario, which is not the problem our research wants to discuss too.

Proposition 3. If $\pi_{k}^{l}>\pi_{k^{\prime}}^{g}$, that is $\delta>\frac{p_{k}-c_{k}^{g}}{2 p_{k}-c_{k}^{l}-c_{k}^{g}}$, then the equilibrium point $(0,1,0)$ is an ESS. If $\pi_{k}^{l}<\pi_{k^{\prime}}^{g}$, that is $\delta<\frac{p_{k}-c_{k}^{g}}{2 p_{k}-c_{k}^{l}-c_{k}^{g}}$, then the equilibrium point $(0,1,0)$ is a saddle point (Proof A3 see in Appendix A).

Proposition 3 shows governments and the public both are not needed to do the regulation and supervision work, and all manufacturers could adopt low-carbon technology independently. However, in practice, since there is no obvious difference between the products manufactured with low-carbon technology or not, the manufacturer's profits will be reduced-and even lead to financial losses if manufactures adopt low-carbon technology when consumers have not a low-carbon preference, or there is no carbon labelling in the market for consumers to distinguish. There are many uncertainties for manufacturers to carry out low-carbon manufacturing independently. So, this is the ideal consequence.

Proposition 4. If $R<C_{r}, \pi_{k}^{l}<\pi_{k}^{g}-T, C_{s}<R$ are true synchronously, the equilibrium point $(0,0,1)$ is an ESS. Otherwise, the equilibrium point $(0,0,1)$ is a saddle point (Proof A4 see in Appendix A).

Proposition 4 shows there is still uncertainty about the behavioral strategy of manufacturers who is willing to apply low-carbon manufacturing. The supervision with public participation only cannot effectively restrict the production behavior of manufacturers.

Proposition 5. The equilibrium point $(1,1,0)$ is a saddle point of replicator dynamic system (Proof A5 see in Appendix A).

Proposition 5 shows that although the carbon taxes and subsidies implemented by the government can effectively make up for the profit difference, the diffusion among manufacturers still cannot be 
sustained. Chen and Hu [47] also shown that the evolutionary strategy of both governments and manufacturers in this scene will present an infinite cycle.

Proposition 6. The equilibrium point $(1,0,1)$ is a saddle point of replicator dynamic system (Proof A6 see in Appendix A).

Proposition 6 shows governments and the public jointly regulate and supervise the enterprises, which will have an effective impact on the behavior strategy of manufacturers and prompt them to implement the low-carbon behavior actively. Of course, the premise for the public to participate in supervision is that the supervision reward given by the government is higher than the supervision cost.

Proposition 7. The equilibrium point $(0,1,1)$ is a saddle point of replicator dynamic system (Proof A7 see in Appendix A).

Proposition 7 shows that only relying on the public to supervise low-carbon behavior, manufacturers may have a fluke in mind and cannot completely adopt low-carbon manufacturing. There is no doubt that the government is the main force in regulating and urging low-carbon activities. So, governments and the public should effectively combine to urge the manufacturers jointly.

Proposition 8. The equilibrium point $(1,1,1)$ is a saddle point of replicator dynamic system (Proof A8 see in Appendix A).

Proposition 8 shows even the joint regulation and supervision by governments and the public cannot urge manufacturers to make full use of low-carbon strategies. Manufacturers take the maximum profit as the goal, and their manufacturing behavior is still highly uncertain. It is also worth pondering how to adjust the governments' environmental regulation and manufacturers' low-carbon strategies after the slowdown in 2014-2016 [1].

From the above analysis, the parameter values in the replicator dynamic system have a crucial influence on the stability of equilibrium points. In the equilibrium solution domain $\Omega=\{(x, y, z) \mid 0<x<1,0<y<1,0<z<1\}$, the eigenvalues of equilibrium point $(x, y, z)$ from the Jacobian matrix present more complex and involve many parameters, which is difficult for stability analysis through Lyapunov stability theory. The mainspring why we develop the model is to grasp the essence of the issue and find the solution to the problem. Hence, if the research objective cannot be fully concluded through theoretical analysis, computer simulation could also predict and analyze the experimental effect of various environmental behaviors.

In the next section, we will assign values to relevant parameters in combination with a case, then analyze the stability of replicator dynamic system with various parameter values through system simulation experiments.

\section{Case and Parameters Setting}

Carbon emissions from China account for $27 \%$ of global carbon emissions, are expected to increase by about $4.5 \%$, which will be higher than the growth rate of global carbon emissions [1]. Food manufacturing is an important energy-consuming industry, which consumes a large amount of energy in the production process. Among the 28 food industries in China, the beer industry is famous for its high energy consumption, high pollution and emissions [48]. Low-carbon manufacturing is one of the important means for the beer industry to change its production mode. The application of carbon dioxide purification technology in beer production can not only reduce coal resources, water and steam consumption, but also shorten the fermentation cycle. If the low-carbon technology is widely adopted in all beer industry, it will save nearly a third of energy consumption [49]. One of the significant peculiarities of the food industry, such as beer, there are essentially indistinguishable whether these products manufactured with low-carbon manufacturing or not. Therefore, this paper will take the beer 
industry as a case for analysis and simulation, but it must be pointed out that the simulation results generated by the example can theoretically be used to many other manufactured products without significant low-carbon peculiarity.

Founded in 1993, China Resources Breweries Co., Ltd. is a national professional beer company, headquartered in Beijing, China. At present, the enterprise operates more than 78 breweries, including snow beer brands and more than 30 regional brands. In 2018, it had an annual capacity of about 21 million liters and a total sales volume of 11.285 million liters, which account for about $29.6 \%$ of the Chinese beer market. In terms of energy-saving and environmental protection, the beer company uses the zero-discharge system for saccharification secondary steam that creates first in China, aiming to achieve the goal of low-carbon and environmental protection production [50]. Referring to the study given in Chen and $\mathrm{Hu}$ [47], our research also selected a bottle of snow-pure beer with $500 \mathrm{~mL}$ as a case to simulate the game model. Using to the Life Cycle Assessment (LCA) approach, Yang et al. calculated the carbon emission of a bottle of snow-pure beer to be $0.42632 \mathrm{~kg} \mathrm{CO} 2 / \mathrm{kg}$ by [51]. In the 4th international low-carbon city forum of China, Jiang Zhaoli [52] states that the potential value of carbon price is $200-300 \mathrm{CNY} /$ ton by 2020 . Suppose the carbon tax rate is $100 \mathrm{CNY} / \mathrm{ton}$, namely $0.1 \mathrm{CNY} / \mathrm{kg}$. Then, the carbon tax of a bottle of snow-pure beer was calculated to be $\mathrm{T}=0.0426 \mathrm{CNY}$, and the corresponding subsidy is $\mathrm{S}=0.142 \mathrm{CNY}$ based on a third of the carbon tax to subsidy proportion [47]. According to market research, a bottle of snow-pure beer sells for 6 to $8 \mathrm{CNY}$ in the retail market, and we assumed the sales price of a bottle of snow-pure beer is $6 \mathrm{CNY}$. On the carbon trading network, the carbon footprint of the premium beer industry was $0.160 .16256 \mathrm{~kg} \mathrm{CO} 2 / \mathrm{kg}$ [53], then the target carbon footprint of a bottle of snow-pure beer could be $0.08128 \mathrm{~kg}$. As a result, the carbon footprint of a bottle of snow-pure beer is still $0.34504 \mathrm{~kg} \mathrm{CO} 2 / \mathrm{kg}$ away from the target carbon footprint, and the price differences of the products with low-carbon technology or not could be $0.03 \mathrm{CNY}$ based on the carbon tax rate. Then, we assumed the unit cost of a bottle of snow-pure beer is $3 \mathrm{CNY}$, and the unit cost of a bottle of snow-pure beer with low-carbon technology could be regarded as $3.03 \mathrm{CNY}$.

Moreover, the purchase preference of consumers is considered in this model. Suppose the total market demand for snow-pure beer is $\varphi=2000$ bottles. Here, the purchase preference of consumers is set to $\delta=0.5$, which represents that the neutrality and randomness of consumers purchasing products. According to the stability analysis of the above model, we first set the regulation cost of government to be the same as supervision reward given by the government. Hence, both regulation cost and supervision reward are first set to $C_{r}=15$ and $R=15$. The public can participate in low-carbon management as a third-party supervision institution. Its supervision cost is relatively small than the regulation cost of government. Here, the supervision cost of publics is first set to $C_{s}=8$. Simultaneously, the initial time is set to $t=0$, and the end time of the evolutionary program is set to $t=10$. Finally, MATLAB is used to simulate and analyze the model with initial parameters.

The initial notations for the simulation analysis are shown in Table 3.

Table 3. Initial notations for the simulation.

\begin{tabular}{ccccccccccccc}
\hline Notations & $p_{k}$ & $c_{k}^{l}$ & $c_{k}^{g}$ & $\delta$ & $\pi_{k}^{l}$ & $\pi_{k}^{g}$ & $\varphi$ & $S$ & $T$ & $C_{r}$ & $C_{s}$ & $R$ \\
\hline Values & 6 & 3.03 & 3 & 0.5 & 3000 & 2970 & 2000 & 14.2 & 42.6 & 15 & 8 & 15 \\
\hline
\end{tabular}

\section{Simulation and Discussion}

\subsection{The Influence of $C_{r}$ on Multi-Stakeholders' Evolutionary Behavior}

The parameter values of $C_{r}$ are set to $12,15,18$, and 20, respectively while other parameters remain constant, to explore the influence of the change of government regulation cost on the evolutionary relationship among the multi-stakeholders. As shown in Figure 5, at $C_{r}=12$ and $C_{r}=15$, the regulation cost of government is relatively low, and the government is the main force for carbon emission control. At $C_{r}=12$, the possibilities of government regulation and low-carbon manufacturing fluctuate widely. Although the maximum possibility of low-carbon behavior chosen by manufacturers is more than that 
of government regulation, this advantage is not significant. At $C_{r}=15$, the possible ranges of both government regulation and manufacturers' low-carbon manufacturing are reduced. Particularly, the maximum possibility of low-carbon manufacturing is less than that of government regulation. In this case, government regulation has no effective binding force on manufacturers' behavior.

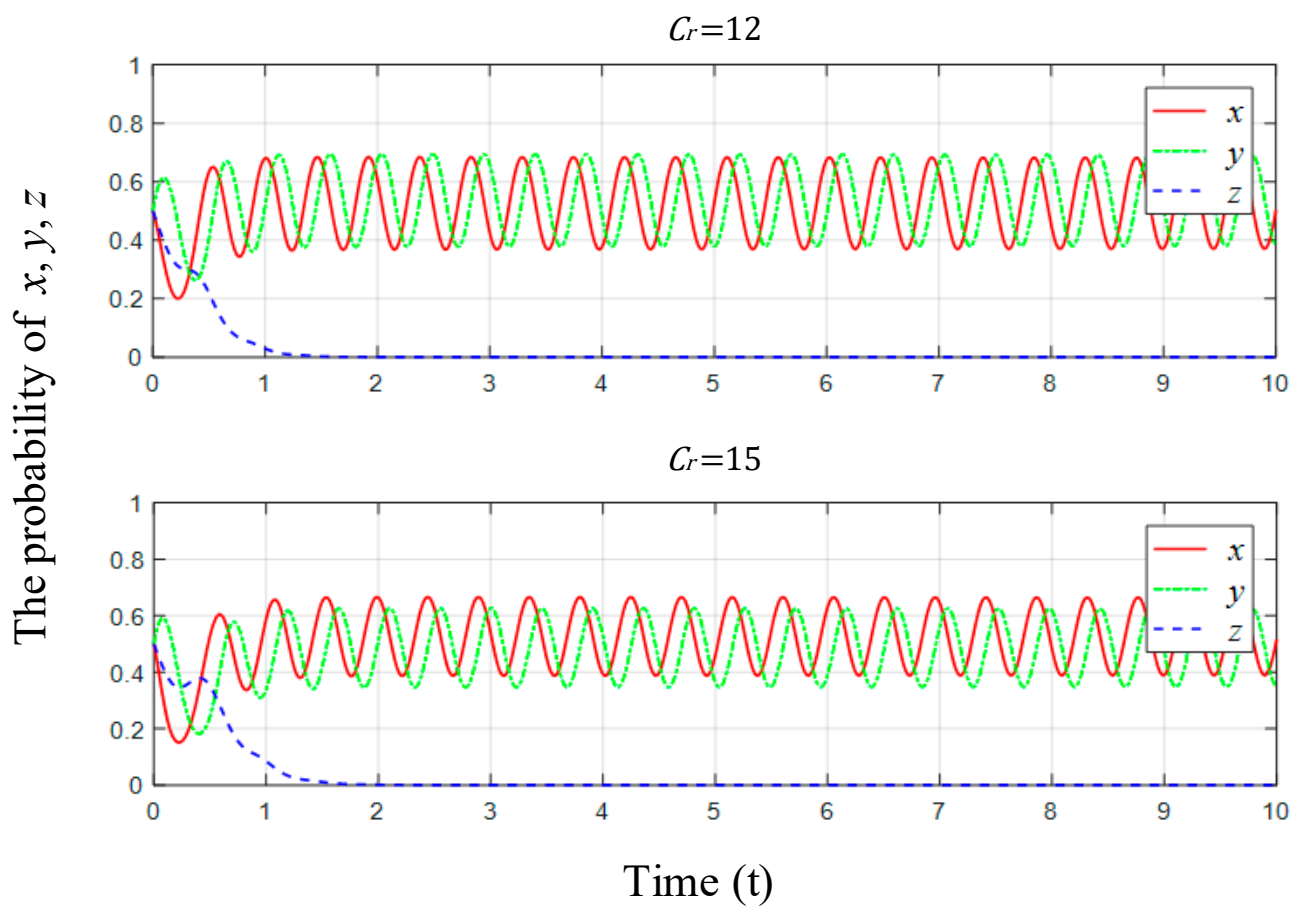

Figure 5. The multi-stakeholders' evolutionary behavior at $C_{r}=12$ and $C_{r}=15$.

As shown in Figure 6, at $C_{r}=18$ and $C_{r}=20$, the regulation cost of government is relatively high, and the government could allocate some governance power to the public to assist in supervising manufacturers' behaviors. Whether at $C_{r}=18$ or $C_{r}=20$, the maximum possibility of low-carbon manufacturing adopted by manufacturers is less than that of public supervision. At $C_{r}=18$, the possible range of public supervision and low-carbon manufacturing is smaller than that at $C_{r}=20$. However, at $C_{r}=20$, the maximum possibilities included publics supervision, and manufacturers' low-carbon behavior are both higher than that at $C_{r}=18$. It shows that government regulation cost increases, and publics also need to strengthen their supervision capacity, which will have a deterrent effect on manufacturers. However, weak government regulation often leaves manufacturers opportunistic, and their low-carbon manufacturing behaviors are also highly unstable.

Figure 7, respectively, shows the evolutionary path under the corresponding regulation costs of governments among the multi-stakeholders. Although the publics participate in supervising of manufacturers' behavior, due to the complexity of regulation procedures for manufacturers, the pressure of government regulation gradually increases, and manufacturers' low-carbon strategy presents great volatility. The result also confirms the leading role of governments in the adoption of low-carbon technology by manufacturers. 


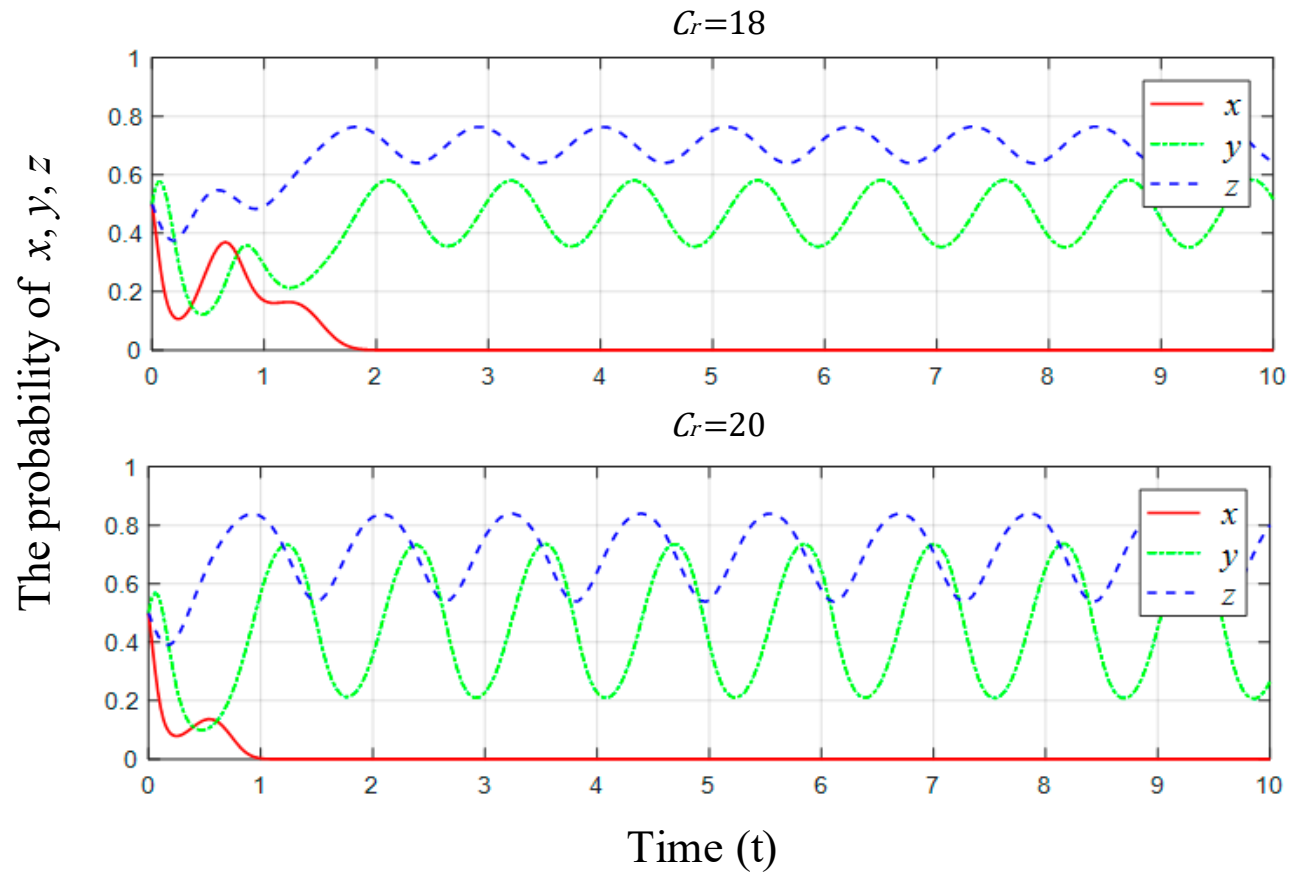

Figure 6. The multi-stakeholders' evolutionary behavior at $C_{r}=18$ and $C_{r}=20$.

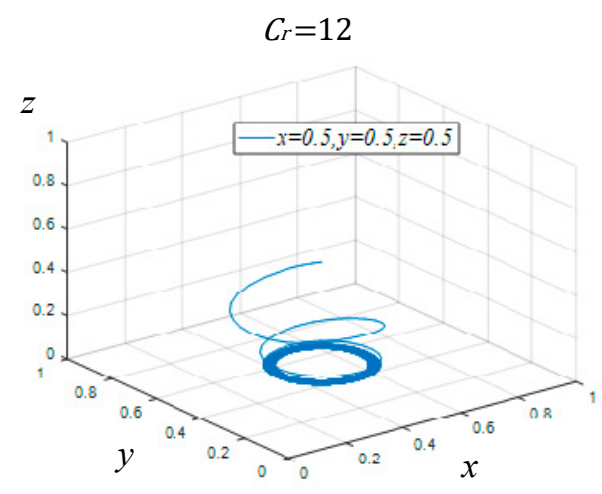

(a)

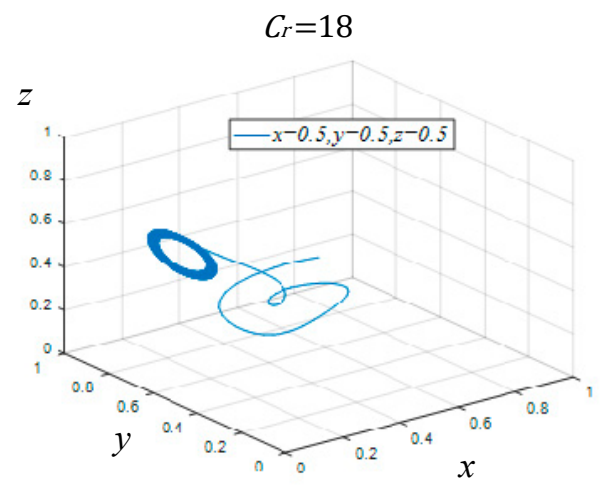

(c)

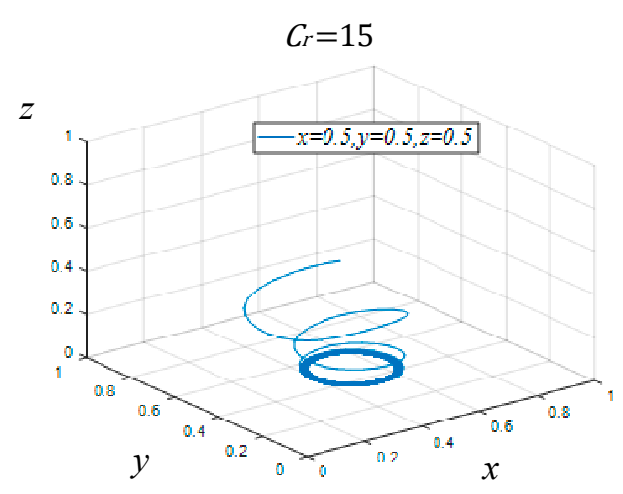

(b)

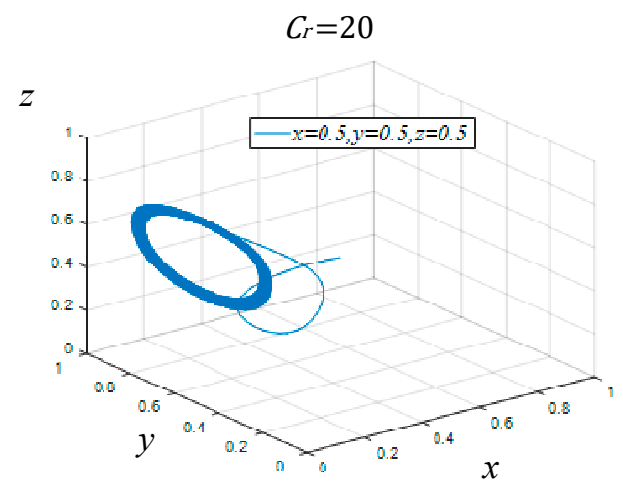

(d)

Figure 7. The tripartite evolutionary behavior in various regulation costs. 


\subsection{The Influence of $R$ on Multi-Stakeholders' Evolutionary Behavior}

The parameter values of $R$ are set to $12,15,18$, and 20, respectively while other parameters remain constant, to explore the influence of the change of supervision reward for the public on the evolutionary relationship among the multi-stakeholders. As shown in Figure 8, at $R=12$ and $R=15$, the supervision reward for the public organization is less than the regulation cost of government, the public is not active in the supervision of low-carbon behavior, the government is the main force for carbon emission reduction. Simultaneously, the possibilities included government regulation and low-carbon manufacturing both fluctuate greatly. At $R=15$, the maximum probability of manufacturers choosing low-carbon technology is less than that at $R=12$, the fluctuation ranges of possibility included government regulation, and low-carbon manufacturing are both less than that at $R=12$ too. No matter at $R=12$ or $R=15$, the maximum probability of government regulation is higher than that of low-carbon manufacturing. In this case, governments should gradually decentralize governance rights and give more rewards to the public for supervision.

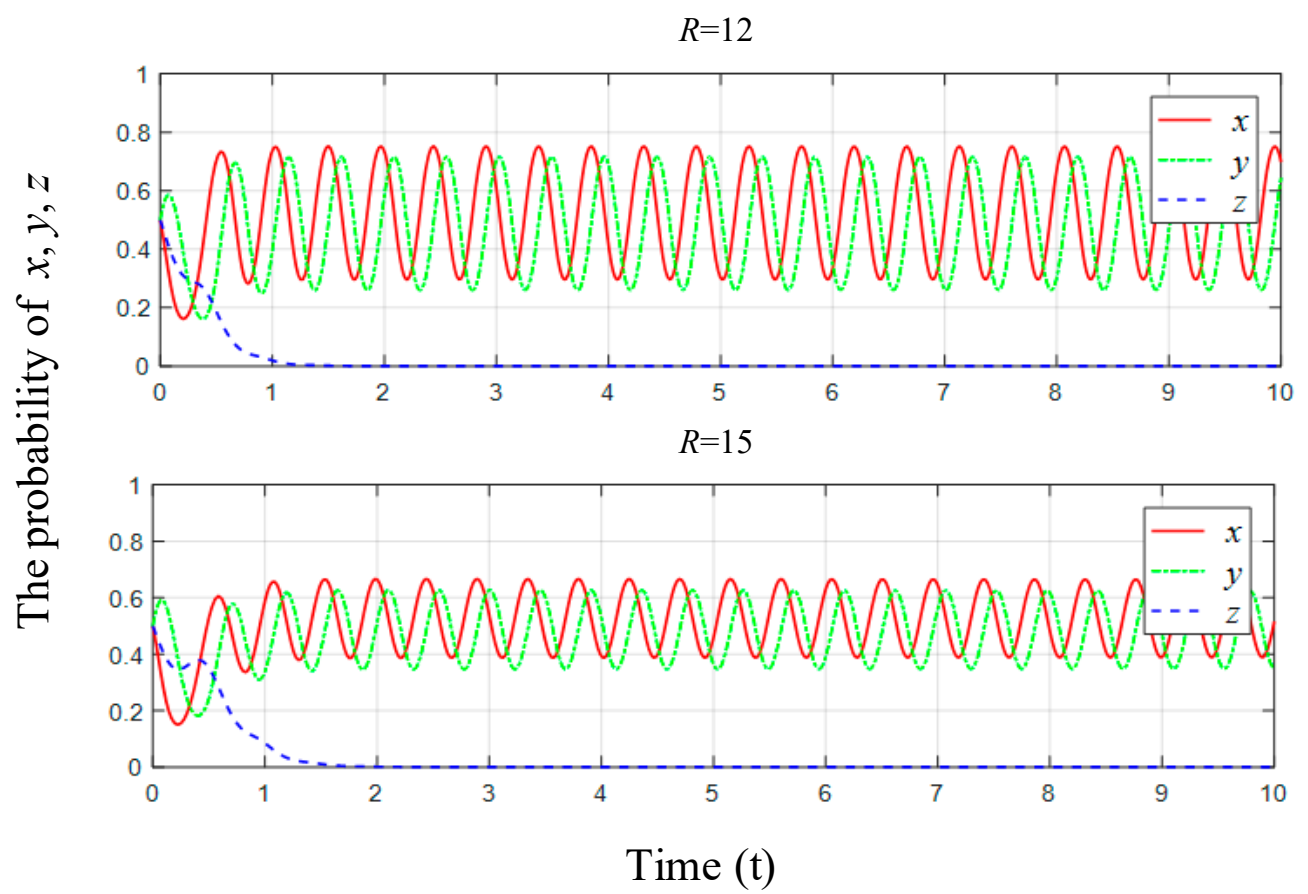

Figure 8. The multi-stakeholders' evolutionary behavior at $R=12$ and $R=15$.

As shown in Figure 9, at $R=18$ and $R=20$, the public mainly supervises the manufacturers with financial support from governments. If the supervision reward for the public is greater than the regulation cost, the focus of carbon emission reduction will be transferred to the public. At $R=20$, the possible range of produced by low-carbon technology gradually narrowed and the maximum possibility of low-carbon manufacturing remained consistent compared at $R=18$. It means that the possibility frequency of manufacturers' low-carbon behavior rises with the increase of the supervision reward for the public. Governments should gradually decentralize governance rights and give more rewards to the public for supervision.

Figure 10 shows the evolutionary path under the corresponding supervision rewards for the public among the multi-stakeholders. The evidence shows that increasing government incentives for the public to monitor and attract third-party supervision is an effective way to promote the adoption of low-carbon technology. 

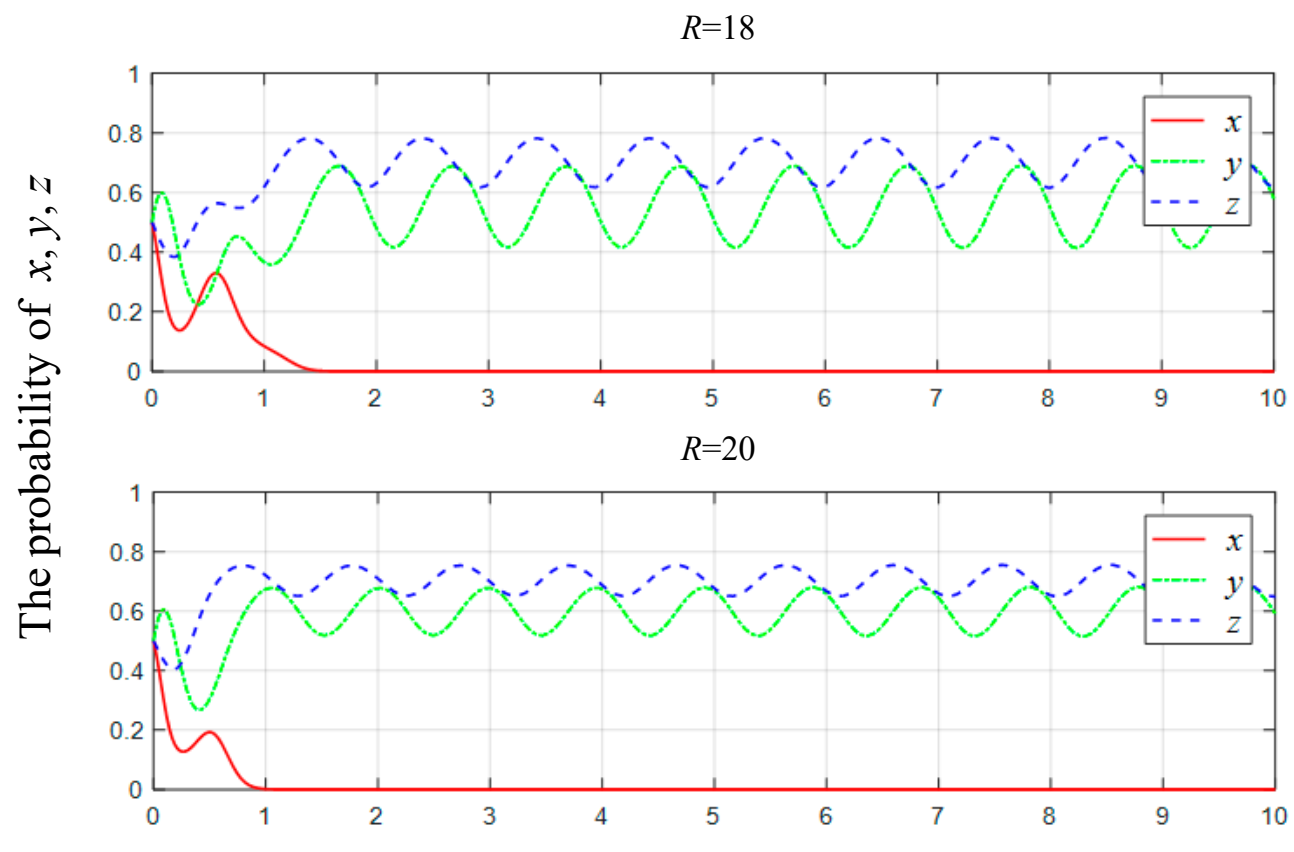

Time (t)

Figure 9. The multi-stakeholders' evolutionary behavior at $R=18$ and $R=20$.

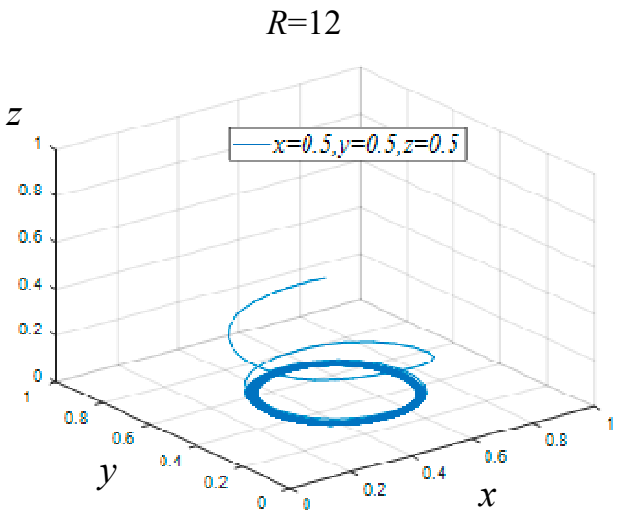

(a)

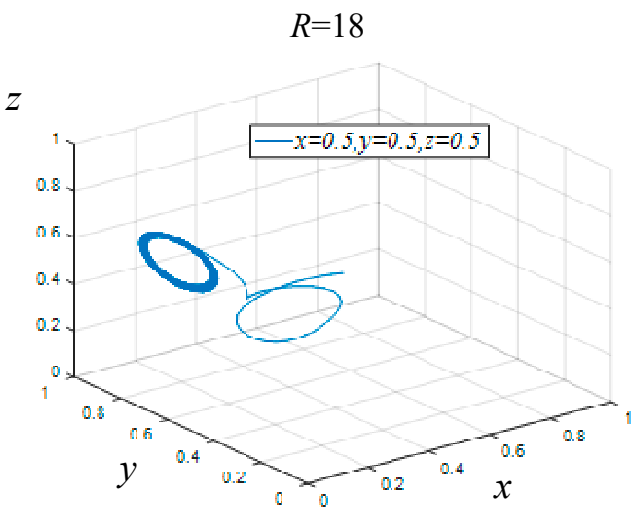

(c)

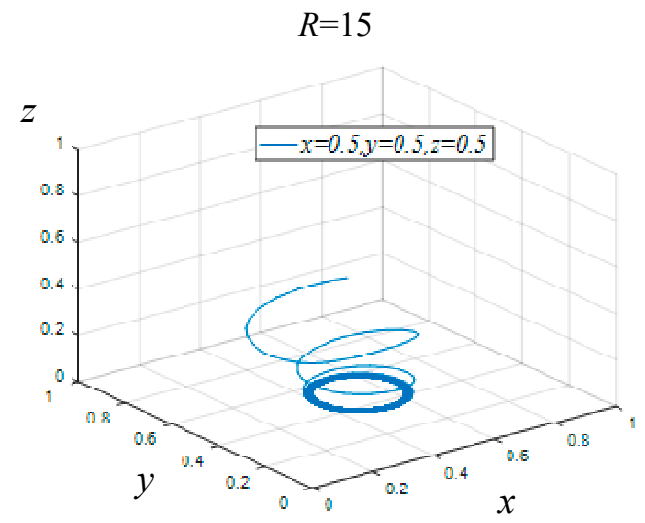

(b)

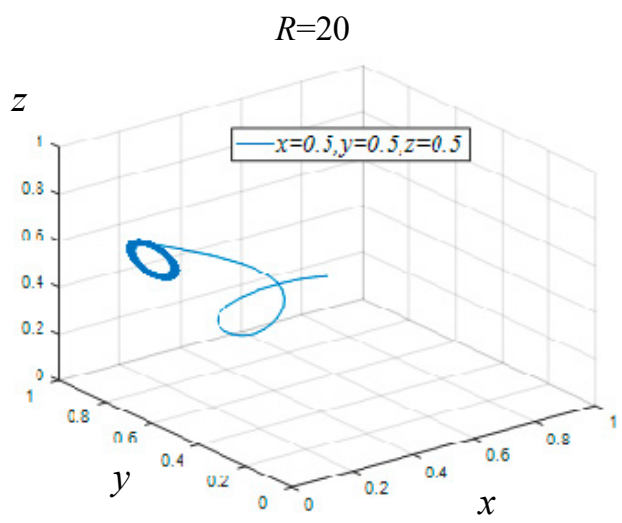

(d)

Figure 10. The tripartite evolutionary path in various supervision rewards. 


\subsection{The Influence of $C_{s}$ on Multi-Stakeholders' Evolutionary Behavior}

The parameter values of $C_{s}$ are set to $10,8,6$, and 3, respectively, while other parameters remain constant, to explore the influence of the change of publics' supervision cost on the evolutionary relationship among the multi-stakeholders. As shown in Figure 11, at $C_{s}=10$ and $C_{s}=8$, the government becomes the key force controlling the production behavior of manufacturers, and the public gradually withdraws from the supervision. Although at $C_{s}=10$, the probability of government regulation and low-carbon manufacturing fluctuates greater, the maximum possibilities of government regulation and manufacturers adoption are both higher compared at $C_{s}=8$. Whether at $C_{s}=10$ and $C_{s}=8$, the possibility of public supervision is more than that of low-carbon manufacturing. The effect of government regulation is not obvious. It also indicates that with the decrease in supervision cost of public, the possibility of government regulation on manufacturers decreases. On the contrary, the possibility of publics participating in supervision is increased.

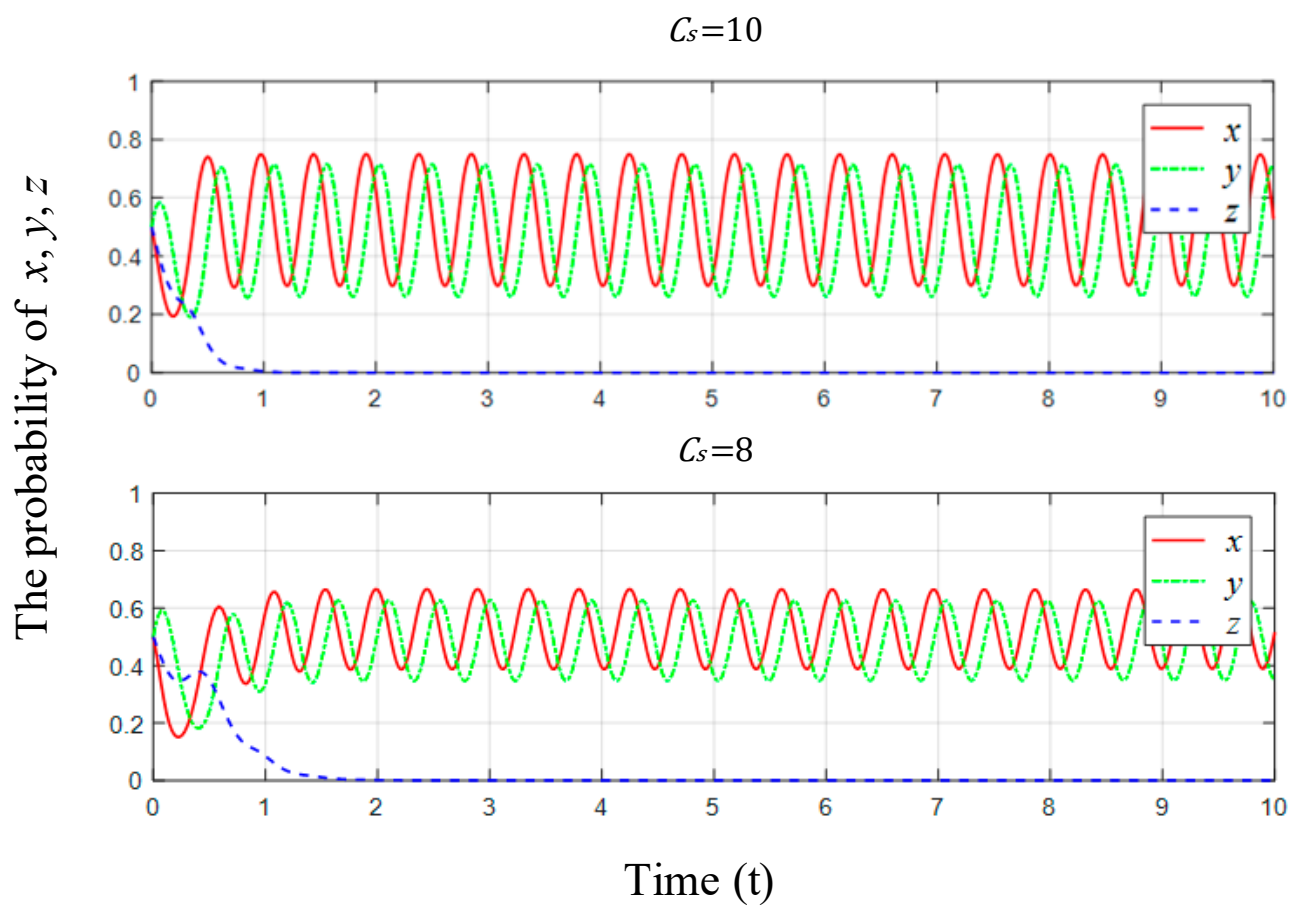

Figure 11. The multi-stakeholders' evolutionary behavior at $C_{s}=10$ and $C_{s}=8$.

As shown in Figure 12, at $C_{s}=6$ and $C_{s}=3$, the supervision cost of the public is relatively low, and the government will gradually devolve the governance rights, the publics mainly exercise power to supervise manufacturers. At $C_{s}=3$, the maximum possibility of low-carbon manufacturing can be up to 0.98 . Compared at $C_{s}=6$, the maximum possibility of it is increased by 0.18 . With the supervision cost of the public decreases, the possibility of low-carbon manufacturing heightens obviously, and the possible range of publics supervision reduces slightly. The reduction of public supervision cost can effectively promote the decentralization of government governance rights, not only can effectively reduce the financial pressure of the government, but also facilitate the public to participate in the supervising of carbon emission control.

Figure 13, respectively, shows the evolutionary path under the corresponding supervision costs for the public among the multi-stakeholders. The public that composed of the people is characterized by wide distribution and low operating costs. Publics can also use information advantages to supervise the illegal behaviors within the industry, which not only reduces the supervision cost, but also improves the supervision effect. 


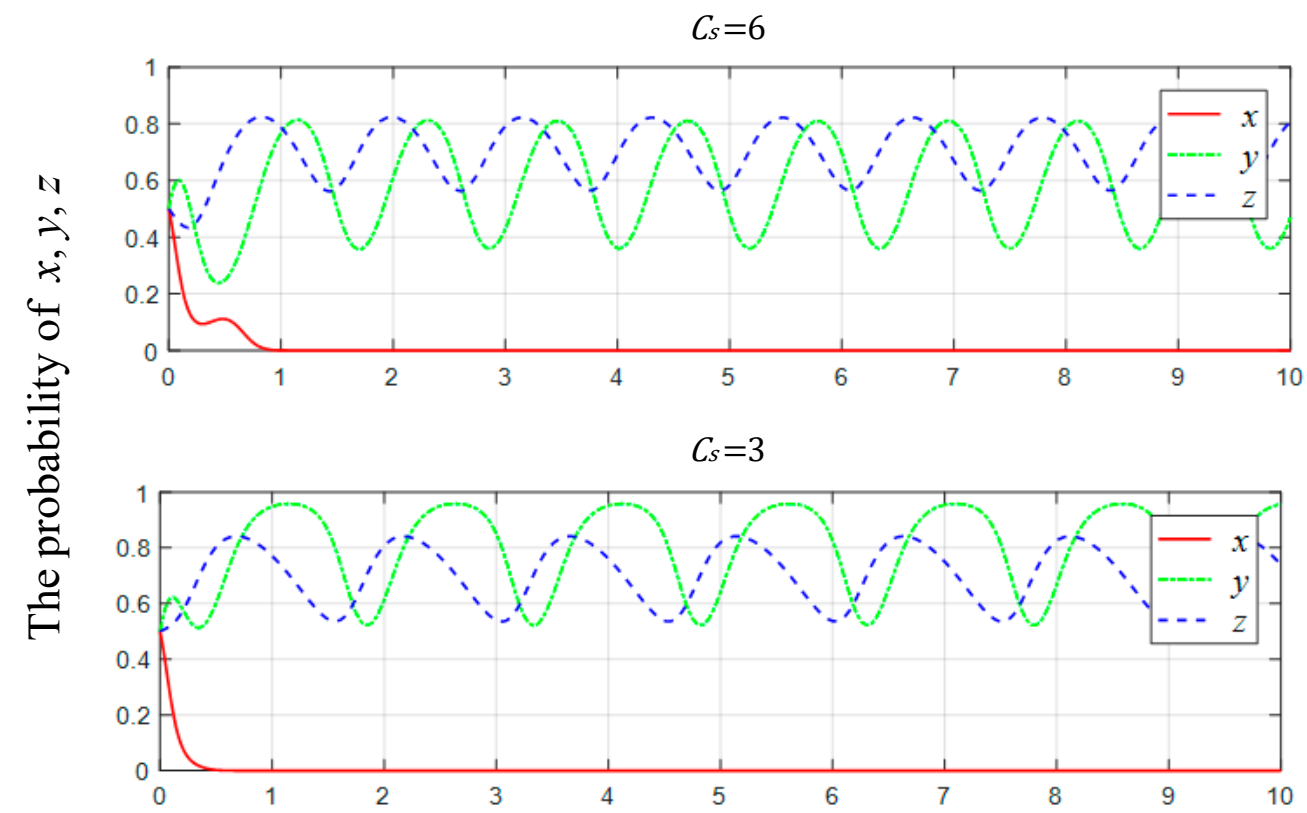

Time (t)

Figure 12. The multi-stakeholders' evolutionary behavior at $C_{s}=6$ and $C_{s}=3$.

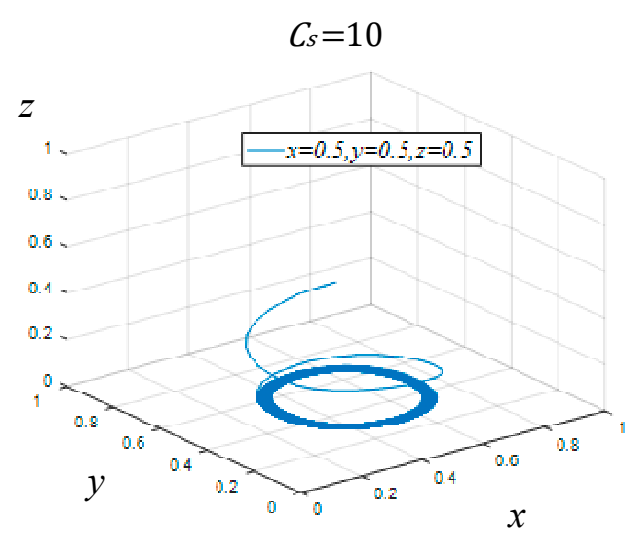

(a)

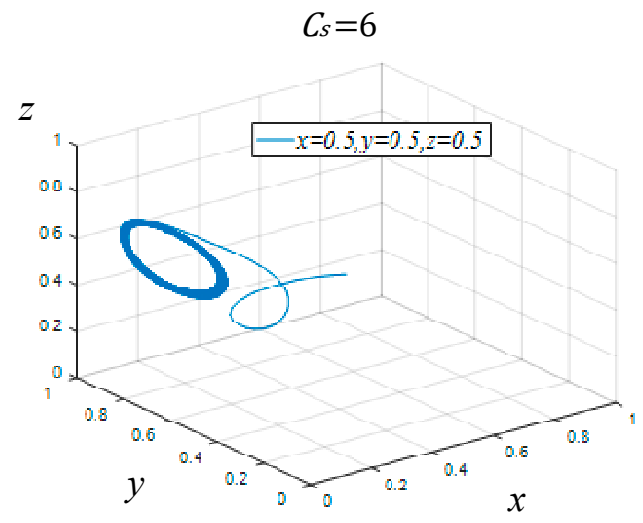

(c)

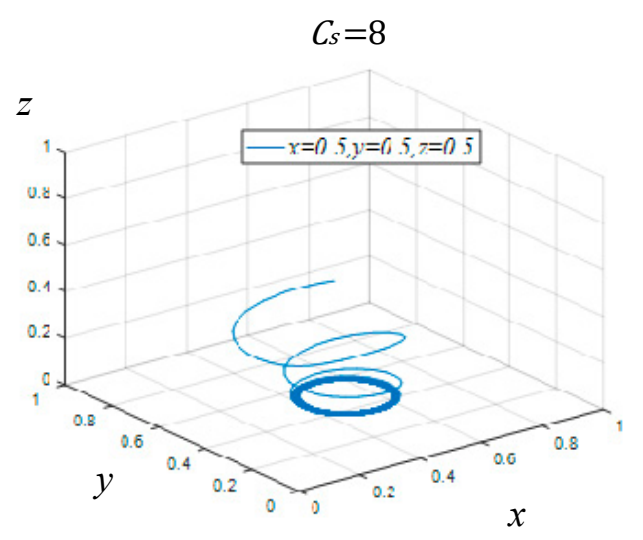

(b)

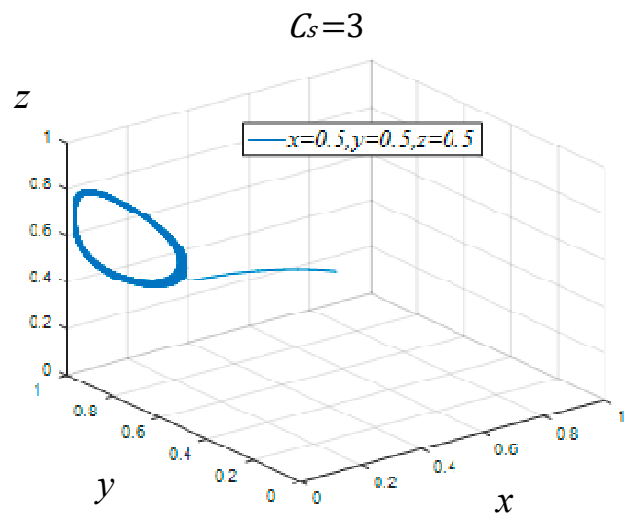

(d)

Figure 13. The tripartite evolutionary path in various supervision costs. 


\subsection{The Influence of T and S on Manufacturers' Evolutionary Behavior}

As shown in Figure 14a, we simulate the scenarios where parameter values of $T$ are increased and decreased by five, respectively, to explore the influence of the change of carbon taxes levied by the government on the low-carbon behavior. This suggests that as carbon taxes rise, the possibility of low-carbon manufacturing would increase quickly. It also confirms that the carbon taxes are positively correlated with the probability of low-carbon manufacturing, and also verifies that the importance of carbon taxes to manufacturers' low-carbon behaviors. Similarly, we simulate the scenarios where parameter values of $S$ are increased and decreased by five, respectively, in Figure 14b. As we can see, the possible range of low carbon production by manufacturers is shrinking. With the increase of low-carbon subsidies, the maximum possibility of produced by low-carbon technology is significantly lower. It also suggests that not all low-carbon subsidies can improve manufacturers' carbon emissions.

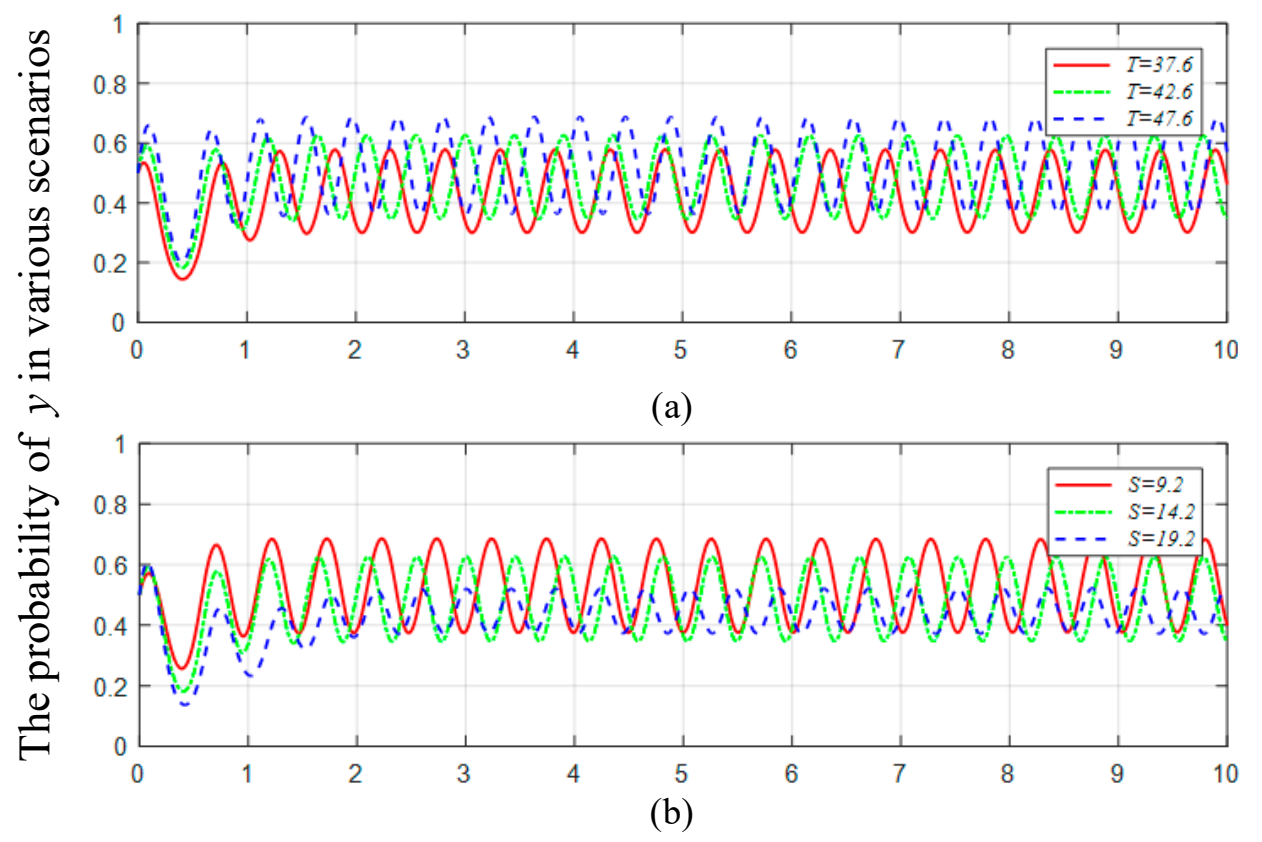

Time (t)

Figure 14. The manufacturers' evolutionary behavior in various carbon taxes and subsidies.

\subsection{The Influence of $\delta$ on Multi-Stakeholders' Evolutionary Behavior}

According to Section 5, profit differentials among manufacturers using low-carbon technology are the main factor in the popularity of low-carbon technologies. Consumers' green preferences can have an important impact on the profit growth of manufacturers. Therefore, this paper also considers the buying preference of consumers in the model. Under the premise of the government's carbon labeling system, we simulate the scenarios where parameter values of $\delta$ are greater and less than 0.5 , respectively, to explore the influence of purchase preferences for customers on the evolutionary relationship among the three stakeholders. As shown in Figure 15, at $\delta>0.5$, the possibility of low-carbon manufacturing would reach $100 \%$. On the contrary, at $\delta<0.5$, the possibility of low-carbon manufacturing should reach $0 \%$. Figure 16, respectively, shows the evolutionary path under the corresponding consumers' preferences among governments, manufacturers and the public. The results show that both governments and publics do not need to regulate, and manufacturers will choose to adopt low-carbon technology independently if consumers prefer low-carbon products. Certainly, this is the ideal result. In practice, there is no perfect carbon labeling system to support these low-carbon 
products. For manufactured goods, without the carbon labelling, consumers would not be able to identify which products were produced using low-carbon technology.

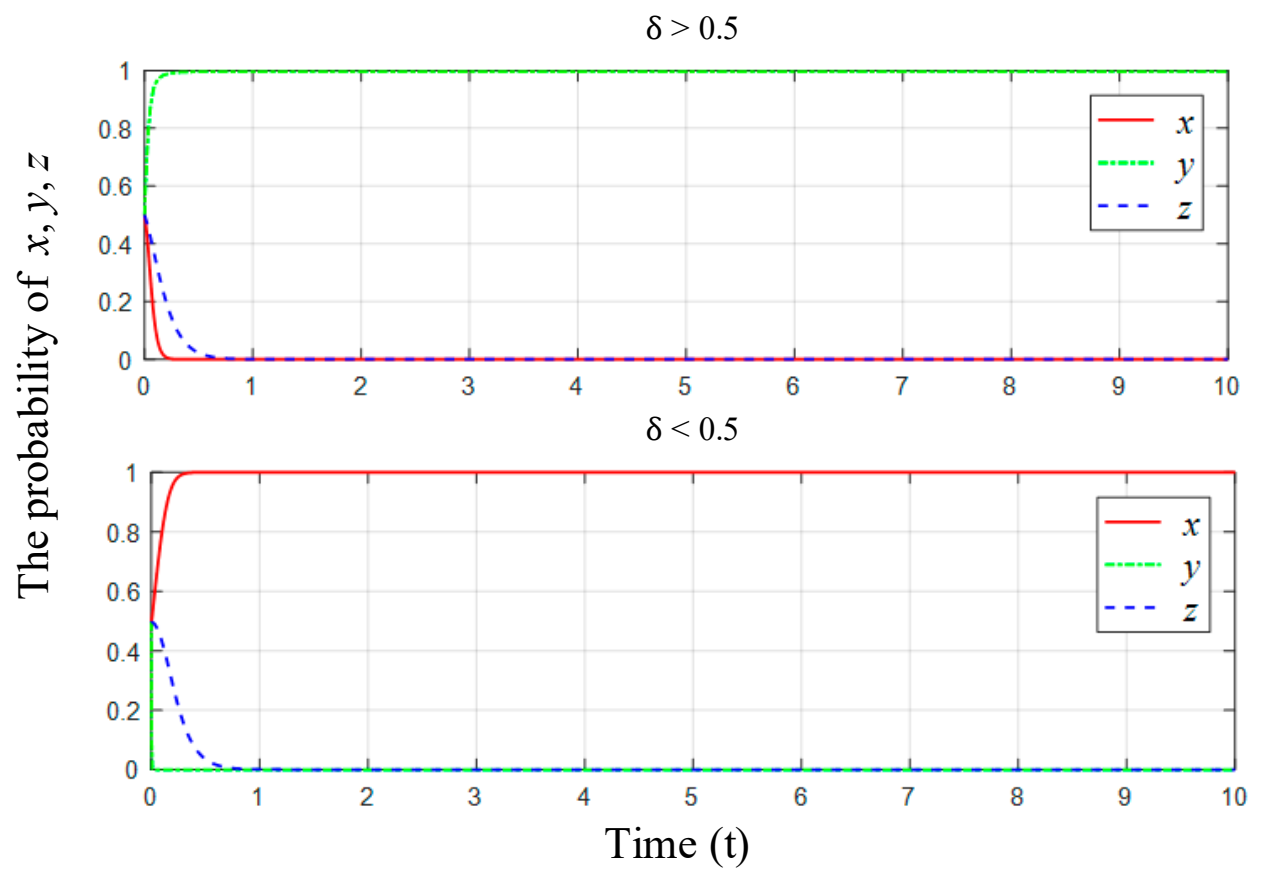

Figure 15. The multi-stakeholders' evolutionary behavior at $\delta>0.5$ and $\delta<0.5$

$\delta>0.5$

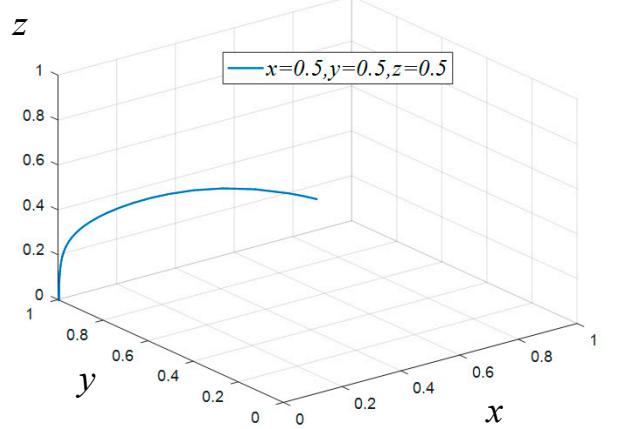

(a)

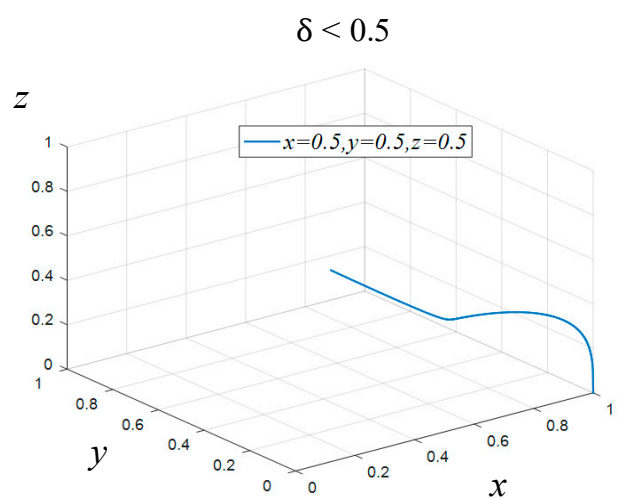

(b)

Figure 16. The tripartite evolutionary path in various purchase preferences.

\section{Conclusions and Policy Implications}

This paper applied EGT to explore how the public intervenes and the impact of interaction relationship between governments and the public under the carbon taxes and subsidies on the low-carbon strategy chosen by manufacturers. Some conclusions and implications about environmental management can be provided as follow.

(1) Carbon taxes and subsidies are effective measures to promote the popularity of low-carbon manufacturing. However, while formulating low-carbon policies, the government will also encounter various in-deep and uncertain impact factors, so it is hard to have enough time and cost to refine the regulation rules [47]. The financial, personnel, and resources of governments are limited. The timeliness of carbon emission regulation and the complexity of the supervision procedure both lead to the difficulty of government regulation. The public as a "third party" to participate in environmental management has become a global consensus, and they can effectively assist the government in supervising the 
production of manufacturers. Notably, whether the environmental management participants are diverse or not, we should always adhere to the dominant position of governments, not to mention the responsibility of governments in the process of low-carbon development.

(2) Publics are the carriers of carrying on government functions. By increasing the supervision reward for the public, governments gradually guide the public to supervise the carbon emission control, aiming to give full play to the social power of the public. The evidence shows that increasing government incentives for the public to attract third-party supervision is an effective way to promote the adoption of low-carbon technology. Publics have the advantages of independence, low cost and flexible form of democratic supervision, and can bear part of the responsibility of democratic supervision. The low cost of public participation in supervision is an effective reflection to make up for the lack of government regulation. However, the development of the public still faces many problems at the present stage. Governments will establish and improve a nationwide action system with the participation of the whole society, form social action networks of different sizes and at different levels, work together to find ways and means to solve environmental problems, and achieve coordinating development of the environment, economy and society.

(3) The governments and the public have a complementary and coordinating relationship. There is a degree of substitution between public supervision and government regulation. The regulation cost of government, the supervision reward for the public and the supervision cost of the public can all influence the behavioral strategies among governments, manufacturers and the public. With the regulation cost strengthens dramatically, governments can consider increasing the supervision reward to support the public to participate in the management of manufacturers' behaviors. At the same time, the public should also actively improve their management ability to reduce their supervision costs in order to jointly urge manufacturers' low-carbon manufacturing with governments. Third-party supervision is not an isolated existence, but a component of regulation, which forms a complete management system with the original subject. Governments should strengthen the interaction between the departments and the third-party institutions in the society, and promote the construction of the cooperation system in the business field.

(4) Carbon taxes are a more effective way of promoting low-carbon manufacturing than low-carbon subsidies. This is consistent with the conclusion of Chen and Hu [47]. In terms of the product lifecycle, some of these products, such as fuel cars, expel more carbon in the process of use than in the production, so it is more important for the government to emphasize carbon taxes in the future. In the early days of low-carbon innovation, the government used abundant subsidies to encourage manufacturers to popularize low-carbon manufacturing. However, not all subsidies make the most of their usefulness. For example, some government subsidies consequentially bring about instances of fraud, proving that not all subsidies are conducive to promoting the popularization of low-carbon technologies. As low-carbon technologies become more mature and popular, manufacturers themselves have enough capacity to continue to choose low-carbon technologies, and the government should gradually reduce the subsidies. In addition, China has not yet established a unified national carbon tax system, and the environmental tax imposed is so widespread that it urgently needs to improve a special carbon tax policy [54].

(5) Low-carbon consumption has become an important link in the development of low-carbon mode and reflects the moods, values and tastes of consumers. Consumers' purchase preference for low-carbon products can encourage manufacturers to adopt low-carbon technology to make up the difference between the cost and the selling price through sales volume. Different from products with significant low-carbon peculiarity like new energy vehicles, commodities, such as food products have no obvious difference in whether the products themselves produced by low-carbon technology or not. Under these circumstances, without a carbon label system, even if consumers are environmentally conscious and willing to purchase green products, they will not be able to recognize which products are made by the low-carbon process, and which are not. As a result, governments should gradually improve 
the carbon label system to help consumers identify low-carbon products, and then manufacturers can independently implement low-carbon manufacturing into their long-term development strategy.

This paper only uses the evolutionary game theory to explore the participation of the public in the supervision of manufacturers' production behavior under carbon taxes and subsidies. Moreover, there are various ways and methods of public participation in environmental management. In the future, we can also expand the channels for the public to participate in environmental management, and investigate the impact of different ways of publics' participation on manufacturers' low-carbon behaviors.

Author Contributions: Conceptualization and methodology, W.C. and Z.-H.H.; writing-original draft preparation, W.C.; writing-review and editing, Z.-H.H.; supervision, Z.-H.H. All authors have read and agreed to the published version of the manuscript.

Funding: This research was funded by the National Natural Science Foundation of China, grant number 71871136, and the Science and Technology Commission of Shanghai Municipality, grant number 17DZ2280200.

Conflicts of Interest: The authors declare no conflict of interest.

\section{Appendix A}

Proof A1. When the equilibrium point is $(0,0,0)$, the Jacobian matrix is:

$$
\left[\begin{array}{ccc}
T-C_{r} & 0 & 0 \\
0 & \pi_{k}^{l}-\pi_{k}^{g} & 0 \\
0 & 0 & R-C_{s}
\end{array}\right]
$$

The eigenvalues of the equilibrium point $(0,0,0)$ by solved are $\lambda=\left[\begin{array}{c}T-C_{r} \\ \pi_{k}^{l}-\pi_{k}^{g} \\ R-C_{s}\end{array}\right]$. If all three eigenvalues are negative numbers, then $(0,0,0)$ is the ESS of replicator dynamic system. If one or more eigenvalues are not negative numbers, then $(0,0,0)$ is the saddle point of replicator dynamic system.

Proof A2. When the equilibrium point is $(1,0,0)$, the Jacobian matrix is:

$$
\left[\begin{array}{ccc}
-T+C_{r} & 0 & 0 \\
0 & S+T+\pi_{k}^{l}-\pi_{k}^{g} & 0 \\
0 & 0 & -C_{s}
\end{array}\right]
$$

The eigenvalues of the equilibrium point $(1,0,0)$ by solved are $\lambda=\left[\begin{array}{c}-T+C_{r} \\ S+T+\pi_{k}^{l}-\pi_{k}^{g} \\ -C_{s}\end{array}\right] .-C_{s}$ is always a negative number. If the other two eigenvalues are negative numbers, then $(1,0,0)$ is the ESS of replicator dynamic system. If one or two eigenvalues are not negative numbers, then $(1,0,0)$ is the saddle point of replicator dynamic system.

Proof A3. When the equilibrium point is $(0,1,0)$, the Jacobian matrix is:

$$
\left[\begin{array}{ccc}
-S-C_{r} & 0 & 0 \\
0 & -\pi_{k}^{l}+\pi_{k}^{g} & 0 \\
0 & 0 & -C_{s}
\end{array}\right]
$$


The eigenvalues of the equilibrium point $(0,1,0)$ by solved are $\lambda=\left[\begin{array}{c}-S-C_{r} \\ -\pi_{k}^{l}+\pi_{k}^{g} \\ -C_{s}\end{array}\right] .-S-C_{r}$ and $-C_{s}$ are always negative numbers. So only need to discuss the case $-\pi_{k}^{l}+\pi_{k}^{g}$ to judge the nature of the equilibrium point. Given $\pi_{k}^{l}=\left(p_{k}-c_{k}^{l}\right) \delta \varphi, \pi_{k}^{g}=\left(p_{k}-c_{k}^{g}\right)(1-\delta) \varphi, \delta=\frac{p_{k}-c_{k}^{g}}{2 p_{k}-c_{k}^{l}-c_{k}^{g}}$ can be obtained by combining $\pi_{k}^{l}$ and $\pi_{k}^{g}$. Thus, if $\delta>\frac{p_{k}-c_{k}^{g}}{2 p_{k}-c_{k}^{l}-c_{k}^{g}}$, then $(0,1,0)$ is the ESS of replicator dynamic system, if $\delta<\frac{p_{k}-c_{k}^{g}}{2 p_{k}-c_{k}^{l}-c_{k}^{8}}$, then $(0,1,0)$ is the saddle point of replicator dynamic system.

Proof A4. When the equilibrium point is $(0,0,1)$, the Jacobian matrix is:

$$
\left[\begin{array}{ccc}
R-C_{r} & 0 & 0 \\
0 & T+\pi_{k}^{l}-\pi_{k}^{g} & 0 \\
0 & 0 & -R+C_{s}
\end{array}\right]
$$

The eigenvalues of the equilibrium point $(0,0,1)$ by solved are $\lambda=\left[\begin{array}{c}R-C_{r} \\ T+\pi_{k}^{l}-\pi_{k}^{g} \\ -R+C_{s}\end{array}\right]$. If all three eigenvalues are negative numbers, then $(0,0,1)$ is the ESS of replicator dynamic system. If one or more eigenvalues are not negative numbers, then $(0,0,1)$ is the saddle point of replicator dynamic system.

Proof A5. When the equilibrium point is $(1,1,0)$, the Jacobian matrix is:

$$
\left[\begin{array}{ccc}
S+C_{r} & 0 & 0 \\
0 & -S-T-\pi_{k}^{l}+\pi_{k}^{g} & 0 \\
0 & 0 & -C_{s}
\end{array}\right]
$$

The eigenvalues of the equilibrium point $(1,1,0)$ by solved are $\lambda=\left[\begin{array}{c}S+C_{r} \\ -S-T-\pi_{k}^{l}+\pi_{k}^{g} \\ -C_{s}\end{array}\right] \cdot S+C_{r}$ is always a positive number. So, this scene cannot satisfy the requirement that all three eigenvalues are negative numbers, then $(1,1,0)$ is the saddle point of replicator dynamic system.

Proof A6. When the equilibrium point is $(1,0,1)$, the Jacobian matrix is:

$$
\left[\begin{array}{ccc}
-R+C_{r} & 0 & 0 \\
0 & S+T+\pi_{k}^{l}-\pi_{k}^{g} & 0 \\
0 & 0 & C_{s}
\end{array}\right]
$$

The eigenvalues of the equilibrium point $(1,0,1)$ by solved are $\lambda=\left[\begin{array}{c}-R+C_{r} \\ S+T+\pi_{k}^{l}-\pi_{k}^{g} \\ C_{S}\end{array}\right]$. $C_{S}$ is always a positive number. So, this scene cannot satisfy the requirement that all three eigenvalues are negative numbers, then $(1,0,1)$ is the saddle point of replicator dynamic system.

Proof A7. When the equilibrium point is $(0,1,1)$, the Jacobian matrix is:

$$
\left[\begin{array}{ccc}
-S-C_{r} & 0 & 0 \\
0 & -T-\pi_{k}^{l}+\pi_{k}^{g} & 0 \\
0 & 0 & C_{s}
\end{array}\right]
$$


The eigenvalue of the equilibrium point $(0,1,1)$ by solved is $\lambda=\left[\begin{array}{c}-S-C_{r} \\ -T-\pi_{k}^{l}+\pi_{k}^{g} \\ C_{S}\end{array}\right]$. $C_{S}$ is always a positive number. So, this scene cannot satisfy the requirement that all three eigenvalues are negative numbers, then $(0,1,1)$ is the saddle point of replicator dynamic system.

Proof A8. When the equilibrium point is $(1,1,1)$, the Jacobian matrix is:

$$
\left[\begin{array}{ccc}
S+C_{r} & 0 & 0 \\
0 & -S-T-\pi_{k}^{l}+\pi_{k}^{g} & 0 \\
0 & 0 & C_{s}
\end{array}\right]
$$

The eigenvalue of the equilibrium point $(1,1,1)$ by solved is $\lambda=\left[\begin{array}{c}S+C_{r} \\ -S-T-\pi_{k}^{l}+\pi_{k}^{g} \\ C_{S}\end{array}\right] \cdot S+C_{r}$ and $C_{S}$ are always positive number. So, this scene cannot satisfy the requirement that all three eigenvalues are negative number, then $(1,1,1)$ is the saddle point of replicator dynamic system.

\section{References}

1. Global Carbon Project. An Annual Update of the Global Carbon Budget and Trends. Available online: https://www.globalcarbonproject.org/carbonbudget/18/data.htm (accessed on 20 September 2019).

2. Fukui, H.; Miyoshi, C. The impact of aviation fuel tax on fuel consumption and carbon emissions: The case of the US airline industry. Transport. Res. Part D-Transport. Environ. 2017, 50, 234-253. [CrossRef]

3. Yi, Y.; Li, J. The effect of governmental policies of carbon taxes and energy-saving subsidies on enterprise decisions in a two-echelon supply chain. J. Clean. Prod. 2018, 181, 675-691.

4. Haddadsisakht, A.; Ryan, S.M. Closed-loop supply chain network design with multiple transportation modes under stochastic demand and uncertain carbon tax. Int. J. Prod. Econ. 2018, 195, 118-131. [CrossRef]

5. $\mathrm{Xu}, \mathrm{X}$;; Zhang, W.; He, P.; $\mathrm{Xu}, \mathrm{X}$. Production and pricing problems in make-to-order supply chain with cap-and-trade regulation. Omega 2017, 66, 248-257. [CrossRef]

6. d'Agostino, G.; Dunne, J.P.; Pieroni, L. Government Spending, Corruption and Economic Growth. World Dev. 2016, 84, 190-205.

7. Arminen, H.; Menegaki, A.N. Corruption, climate and the energy-environment-growth nexus. Energy Econ. 2019, 80, 621-634. [CrossRef]

8. Schroeder, P. Assessing effectiveness of governance approaches for sustainable consumption and production in China. J. Clean. Prod. 2014, 63, 64-73. [CrossRef]

9. Sun, L.; Zhu, D.; Chan, E.H.W. Public participation impact on environment NIMBY conflict and environmental conflict management: Comparative analysis in Shanghai and Hong Kong. Land Use Pol. 2016, 58, 208-217. [CrossRef]

10. Yew, W.L.; Zhu, Z. Innovative autocrats? Environmental innovation in public participation in China and Malaysia. J. Environ. Manag. 2019, 234, 28-35. [CrossRef]

11. Wittneben, B.B.F. Exxon is right: Let us re-examine our choice for a cap-and-trade system over a carbon tax. Energy Policy 2009, 37, 2462-2464. [CrossRef]

12. Shammin, M.R.; Bullard, C.W. Impact of cap-and-trade policies for reducing greenhouse gas emissions on U.S. households. Ecol. Econ. 2009, 68, 2432-2438. [CrossRef]

13. Galinato, G.I.; Yoder, J.K. An integrated tax-subsidy policy for carbon emission reduction. Resour. Energy Econ. 2010, 32, 310-326. [CrossRef]

14. Jiang, J.; Xie, D.; Ye, B.; Bo, S.; Chen, Z. Research on China's cap-and-trade carbon emission trading scheme: Overview and outlook. Appl. Energy 2016, 178, 902-917. [CrossRef]

15. Sabzevar, N.; Enns, S.T.; Bergerson, J.; Kettunen, J. Modeling competitive firms' performance under price-sensitive demand and cap-and-trade emissions constraints. Int. J. Prod. Econ. 2017, 184, 193-209. [CrossRef] 
16. Wang, S.; Wan, L.; Li, T.; Luo, B.; Wang, C. Exploring the effect of cap-and-trade mechanism on firm's production planning and emission reduction strategy. J. Clean. Prod. 2018, 172, 591-601. [CrossRef]

17. Krass, D.; Ovchinnikov, A. Environmental Taxes and the Choice of Green Technology. Prod. Oper. Manag. 2013, 22, 1035-1055. [CrossRef]

18. Zhao, R.; Zhou, X.; Han, J.; Liu, C. For the sustainable performance of the carbon reduction labeling policies under an evolutionary game simulation. Technol. Forecast. Soc. Chang. 2016, 112, 262-274. [CrossRef]

19. Hafezalkotob, A. Competition, cooperation, and coopetition of green supply chains under regulations on energy saving levels. Transp. Res. Pt. e-Logist. Transp. Rev. 2017, 97, 228-250. [CrossRef]

20. Wang, Z.; He, S.; Zhang, B.; Wang, B. Optimizing cooperative carbon emission reduction among enterprises with non-equivalent relationships subject to carbon taxation. J. Clean. Prod. 2018, 172, 552-565. [CrossRef]

21. He, P.; He, Y.; Xu, H. Channel structure and pricing in a dual-channel closed-loop supply chain with government subsidy. Int. J. Prod. Econ. 2019, 213, 108-123. [CrossRef]

22. Chen, J.-Y.; Dimitrov, S.; Pun, H. The impact of government subsidy on supply Chains' sustainability innovation. Omega 2019, 86, 42-58. [CrossRef]

23. Wen, W.; Zhou, P.; Zhang, F. Carbon emissions abatement: Emissions trading vs consumer awareness. Energy Econ. 2018, 76, 34-47. [CrossRef]

24. Yang, H.; Chen, W. Retailer-driven carbon emission abatement with consumer environmental awareness and carbon tax: Revenue-sharing versus Cost-sharing. Omega 2018, 78, 179-191. [CrossRef]

25. Yenipazarli, A. Incentives for environmental research and development: Consumer preferences, competitive pressure and emissions taxation. Eur. J. Oper. Res. 2019, 276, 757-769. [CrossRef]

26. Feucht, Y.; Zander, K. Consumers' preferences for carbon labels and the underlying reasoning. A mixed methods approach in 6 European countries. J. Clean. Prod. 2018, 178, 740-748. [CrossRef]

27. O'Faircheallaigh, C. Public participation and environmental impact assessment: Purposes, implications, and lessons for public policy making. Environ. Impact Assess. Rev. 2010, 30, $19-27$.

28. Glucker, A.N.; Driessen, P.P.J.; Kolhoff, A.; Runhaar, H.A.C. Public participation in environmental impact assessment: Why, who and how? Environ. Impact Assess. Rev. 2013, 43, 104-111. [CrossRef]

29. Wu, J.; Xu, M.; Zhang, P. The impacts of governmental performance assessment policy and citizen participation on improving environmental performance across Chinese provinces. J. Clean. Prod. 2018, 184, 227-238. [CrossRef]

30. Simpson, N.P.; Basta, C. Sufficiently capable for effective participation in environmental impact assessment? Environ. Impact Assess. Rev. 2018, 70, 57-70. [CrossRef]

31. Li, L.; Xia, X.H.; Chen, B.; Sun, L. Public participation in achieving sustainable development goals in China: Evidence from the practice of air pollution control. J. Clean. Prod. 2018, 201, 499-506. [CrossRef]

32. Zhang, G.; Deng, N.; Mou, H.; Zhang, Z.G.; Chen, X. The impact of the policy and behavior of public participation on environmental governance performance: Empirical analysis based on provincial panel data in China. Energy Policy 2019, 129, 1347-1354. [CrossRef]

33. Kostka, G. Command without control: The case of China's environmental target system. Regul. Gov. 2016, 10, 58-74. [CrossRef]

34. Jing, W.; Chang, I.S.; Yilihamu, Q.; Yu, Z. Study on the practice of public participation in environmental impact assessment by environmental non-governmental organizations in China. Renew. Sust. Energ. Rev. 2017, 74, 186-200.

35. Ayana, A.N.; Arts, B.; Wiersum, K.F. How environmental NGOs have influenced decision making in a 'semi-authoritarian' state: The case of forest policy in Ethiopia. World Dev. 2018, 109, 313-322. [CrossRef]

36. Nowak, M.A.; Karl, S. Evolutionary dynamics of biological games. Science 2004, 303, 793-799. [CrossRef]

37. Requejo, R.J.; Camacho, J. Evolution of cooperation mediated by limiting resources: Connecting resource based models and evolutionary game theory. J. Theor. Biol. 2011, 272, 35-41. [CrossRef]

38. Sikhar, B.; Gaurav, A.; Zhang, W.J.; Biswajit, M.; Tiwari, M.K. A decision framework for the analysis of green supply chain contracts: An evolutionary game approach. Expert Syst. Appl. 2012, 39, 2965-2976. [CrossRef]

39. Ji, P.; Ma, X.; Li, G. Developing green purchasing relationships for the manufacturing industry: An evolutionary game theory perspective. Int. J. Prod. Econ. 2015, 166, 155-162. [CrossRef]

40. Yang, Z.; Shi, Y.; Li, Y. Analysis of intellectual property cooperation behavior and its simulation under two types of scenarios using evolutionary game theory. Comput. Ind. Eng. 2018, 125, 739-750. [CrossRef] 
41. Tian, Y.; Govindan, K.; Zhu, Q. A system dynamics model based on evolutionary game theory for green supply chain management diffusion among Chinese manufacturers. J. Clean. Prod. 2014, 80, 96-105. [CrossRef]

42. Mahmoudi, R.; Rasti-Barzoki, M. Sustainable supply chains under government intervention with a real-world case study: An evolutionary game theoretic approach. Comput. Ind. Eng. 2018, 116, 130-143. [CrossRef]

43. Encarnação, S.; Santos, F.P.; Santos, F.C.; Blass, V.; Pacheco, J.M.; Portugali, J. Paths to the adoption of electric vehicles: An evolutionary game theoretical approach. Transp. Res. Part B Methodol. 2018, 113, $24-33$.

44. Li, J.; Jiao, J.; Tang, Y. An evolutionary analysis on the effect of government policies on electric vehicle diffusion in complex network. Energy Policy 2019, 129, 1-12. [CrossRef]

45. Friedman, D. Evolutionary Games in Economics. Econometrica 1991, 59, 637. [CrossRef]

46. Lyapunov, A.M. The general problem of the stability of motion. Int. J. Control 1992, 55, 531-534. [CrossRef]

47. Chen, $\mathrm{W} . ; \mathrm{Hu}, \mathrm{Z} .-\mathrm{H}$. Using evolutionary game theory to study governments and manufacturers' behavioral strategies under various carbon taxes and subsidies. J. Clean. Prod. 2018, 201, 123-141. [CrossRef]

48. Sun, T.; She, D. Research on the relationship between the international competitiveness of China's manufacturing industry and factor price-Based on the empirical analysis of 28 manufacturing industries (In Chinese). Shanghai Econ. Res. 2016, 05, 10-18, 57.

49. Wang, H.; Wang, F. Study on purification technology of food grade carbon dioxide impurities by adsorption method. Chin. Foreign Wine-Beer Technol. 2017, 6, 20-25. (In Chinese)

50. China Resources Breweries Co. Ltd. A Brief Introduction to China Resources Beer Co.Ltd. [In Chinese]. Available online: http://www.snowbeer.com.cn/ (accessed on 20 September 2019).

51. Yang, J.; Zhong, J.; Zhang, K.; Lu, J. Beer Carbon Footprint and a Case study. Glob. Alcinfo.beer Technol. 2013, 8,6-14. (In Chinese)

52. Fourth International Low-carbon City Forum. Carbon Trading of 200-300 yuan/ton Is the Ideal Value. Available online: http://www.nbd.com.cn/articles/2016-06-20/1014398.html (accessed on 20 September 2019).

53. Carbon Trading Network. Industry Carbon Intensity Advanced Value Data Query List. Available online: www.tanpaifang.com/tanjiliang/2014/0504/31846.html (accessed on 20 September 2019).

54. Weng, Q.; Xu, H. A review of China's carbon trading market. Renew. Sustain. Energy Rev. 2018, 91, 613-619. [CrossRef]

(C) 2020 by the authors. Licensee MDPI, Basel, Switzerland. This article is an open access article distributed under the terms and conditions of the Creative Commons Attribution (CC BY) license (http://creativecommons.org/licenses/by/4.0/). 